\title{
Mindfulness and the aging brain: a proposed paradigm shift
}

\author{
Ruchika Shaurya Prakash*, Angeline A. De Leon, Beth Patterson, Brittney L. Schirda and Alisha L. Janssen \\ Department of Psychology, The Ohio State University, Columbus, OH, USA
}

Edited by:

Rodrigo Orlando Kuljiš, Zdrav Mozak

Limitada, Chile

Reviewed by:

Ana M. Coto-Montes, University of

Oviedo, Spain

Bogdan O. Popescu, Colentina

Clinical Hospital, Romania

*Correspondence:

Ruchika Shaurya Prakash,

Department of Psychology, The

Ohio State University, 1835 Neil

Avenue, Columbus, OH 43210, USA

e-mail:Prakash.30@osu.edu
There has been a proliferation of cognitive training studies investigating the efficacy of various cognitive training paradigms as well as strategies for improving cognitive control in the elderly. While some have found support for the transfer of training, the majority of training studies show modest to no transfer effects. When transfer effects have been observed, the mechanisms contributing to enhanced functioning have been difficult to dissociate. In this review, we provide a theoretical rationale for the study of mindfulness in older adults as a particular type of training program designed to improve cognitive control by capitalizing on older adults' acquired behavioral orientation toward higher socioemotional goals. Given the synergistic relationship between emotional and cognitive control processes, the paradoxical divergence in older adults' functional trajectory in these respective domains, and the harmonious interplay of cognitive and emotional control embedded in the practice of mindfulness, we propose mindfulness training as an opportunistic approach to cultivating cognitive benefits in older adults. The study of mindfulness within aging, we argue, capitalizes on a fundamental finding of the socioemotional aging literature, namely the preferential change in motivational goals of older adults from ones involving future-oriented wants and desires to present-focused emotion regulation and gratification.

Keywords: aging, mindfulness, emotional control, cognitive control, neuroimaging
A central focus of the field of cognitive aging involves securing the quality of life of older adults. This requires, first, an examination and understanding of age-related changes in the fundamental processes of controlled regulatory behavior and secondly, the design and development of intervention programs to reduce such age-related decline in the controlled processes. The centerpiece of this controlled regulatory processing may be theoretically differentiated into the complementary processes of emotional control and cognitive control, which, interestingly show divergent functional trajectories with age. While cognitive control operations have been known to show a steady decline with increasing age (Park et al., 2002; Salthouse, 2010), emotional control, along with overall emotional satisfaction, is well-maintained and sometimes even enhanced in older adults (Carstensen et al., 2000; Charles, 2010; Hay and Diehl, 2011). Furthermore, while engaging in emotional regulation has costs for cognitive control task performance in young adults, older adults do not demonstrate reductions in cognitive control capacity following an emotion regulation instruction, thus suggesting an effortless engagement of such affective regulatory behaviors in older adults (Scheibe and Blanchard-Fields, 2009). In this review article, we provide a rationale for the study of mindfulness training, which, by fundamentally reducing the reactivity of the wandering mind (Bishop et al., 2004), we argue is capable of enhancing both emotional and cognitive control in the aging brain. Given the putative primacy of maintaining emotional well-being and control in older adults (Carstensen, 1993, 2006; Carstensen et al., 1999), mindfulness training, with its emphasis on present-focused attention and regulation of the habitual, reflexive tendencies of the mind, has the potential to enhance cognitive control operations in the elderly and the neural circuitry associated with it.

With the aging of the baby boomer generation (Gavrilov and Heuveline, 2003) and the increasing standard of efficacy to which older adults hold themselves, a critical understanding of the mechanistic organization of cognitive and emotional functioning and their potential flexibility across the developmental lifespan represents the core of current investigative efforts (Hertzog et al., 2009; Lustig et al., 2009; Park and Bischof, 2013). While the makers of brain training games argue the capability of such cognitive training programs to produce broad transfer effects, much of the systematic, scientific study of cognitive training interventions provide modest support for the increase in overall cognitive capabilities of older adults, with limited benefits to tasks of everyday functioning (Willis et al., 2006; Lustig et al., 2009). Recent reviews of the current state of cognitive training literature in the elderly underscores the importance of designing interventions that produce both farreaching transfer effects and enable an understanding of the mechanisms behind such enhanced functioning (Lustig et al., 2009; Park and Bischof, 2013). While strategy training studies are specific and clearly articulate the mediating factors that 
might be responsible for the change in functioning, there has been a consistent failure to produce any far-reaching transfer effects in several of these studies (Dunlosky et al., 2003; Rebok et al., 2007). On the other hand, multi-modal intervention techniques, involving potential lifestyle changes (Fried et al., 2004; Noice et al., 2004; Park et al., 2014), show the most promising effects; however, the ability to clearly parse the mechanisms of action remains a limitation of such approaches. Thus, an ideal training program would be one which pragmatically focuses on older adults' increased socioemotional drive for emotional well-being and satisfaction; demonstrates broad transfer effects to domains of cognitive functioning that directly influence everyday functioning; and facilitates the development of a mechanistic model that explains the role of mediating variables.

We hypothesize, based on the increasing scientific study of mindfulness training (Davidson, 2010; Williams, 2010; Vago and Silbersweig, 2012), that this training approach has the potential to enhance cognitive control and emotional control capabilities in older adults and modify the neural circuitry supporting this controlled regulatory processing. In this article, we provide an overview of the age-related alterations seen as a function of the developmental trajectory, outlining a rationale for the incorporation of both emotional and cognitive aspects of regulatory control in a training program targeting the elderly. We then review the growing literature on mindfulness training, raising critical themes emerging from the systematic investigation of the influence of mindfulness training on emotional and cognitive control. We end by suggesting directions for future research, specifically noting some of the methodological issues that require further attention in this growing field of research.

\section{EMOTION-COGNITION PARADOX IN AGING}

While sharing an integrated neuroarchitecture and operating using a similar dual-process system, when studied in the context of aging, cognitive and emotional control are remarkably divergent. A paradox that has long perplexed the aging research field is the emergence of an age-related enhancement in emotional efficacy in the midst of general diminishment of basic cognitive functioning (see Figure $\mathbf{1}$ for a summary of the key findings). It appears that, at the peak of human development, cognitive control capacity is at its greatest whereas emotion regulation ability is still developing, and that this trend is interestingly reversed with advanced age.

\section{COGNITIVE PROCESSING AND AGING}

Emerging theories of healthy cognitive aging suggest that agerelated variation in cognitive functioning is fundamentally linked

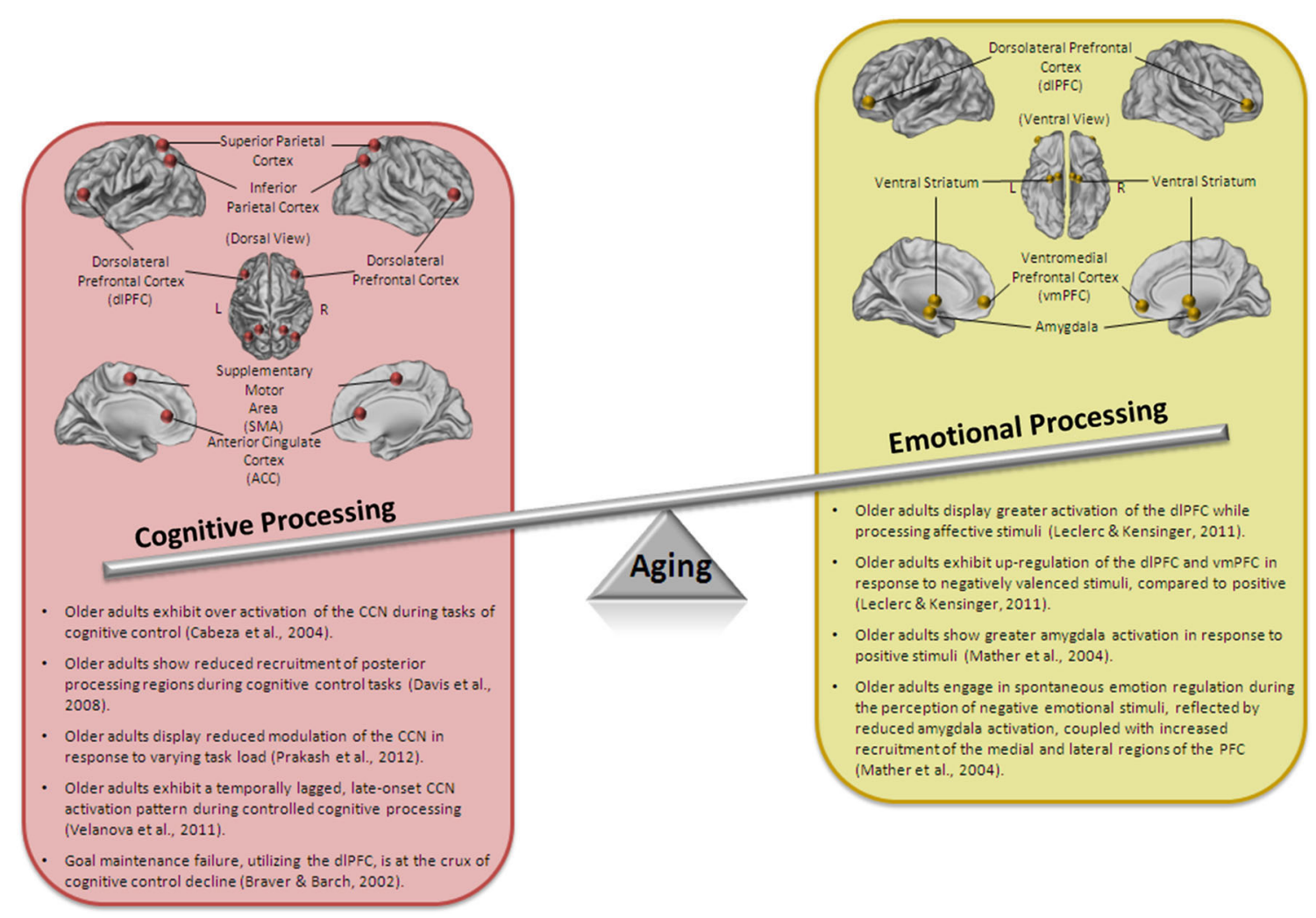

FIGURE 1 | Schematic representation of the aging paradox. Older adults show a decline in cognitive processing, including impaired performance on tasks of cognitive control and alterations in the neural correlates of cognitive control. However, emotional processing, and at times, emotional regulation is well-maintained and even enhanced in older adults. 
to aging-based deficiencies in cognitive control (De Jong, 2001; Braver and West, 2008). There has been unequivocal evidence demonstrating that older adults, in comparison to young adults, consistently demonstrate poorer executive control capabilities, showing marked deficits in the ability to maintain task items online and/or quickly and accurately manipulate information (Park and Reuter-Lorenz, 2009; Goh et al., 2012). Cross-sectional and longitudinal research confirm that older adults experience difficulty performing tasks that require attending and responding to multiple sources of information, with age-related declines in executive processes occurring around 30 years of age and declining steadily across the lifespan (Park and Reuter-Lorenz, 2009).

One of the fundamental findings in this literature has been the inability of older adults to suppress task-irrelevant distractors (Hasher and Zacks, 1988; Gazzaley et al., 2005), suggesting that the impairment in controlled cognitive processing seems to arise from a disturbance in the top-down processing stream, caused by the intrusion of internal or external stimuli. Healthy aging is herein conceptualized as a problem in which the attentional filtering of older adults becomes increasingly diffuse so as to include not only relevant stimuli, but extraneous irrelevant stimuli as well. Older adults, thus show enhanced memory of distractor stimuli as well as attentional overprocessing of task-irrelevant information, which strongly correlates with diminished working memory performance (Gazzaley et al., 2005). Much of this, according to the goal maintenance account proposed by Braver et al. stems from an inability to maintain task-relevant, goal representations and thereby reduce interference from internal or external stimuli (Braver and Barch, 2002; Braver et al., 2005; Rush et al., 2006). In as far as goal maintenance represents a process of resistance to attentional interference, findings implicate that cognitive control decline in the elderly is indeed a problem of impaired top-down modulation, specifically in relation to the component associated with the controlled-attention mechanism of working memory (Gazzaley et al., 2005; Gazzaley, 2013).

Further, the goal maintenance account of cognitive control asserts the involvement of the lateral prefrontal cortices (IPFC) in representing and storing such contextual information (O'Reilly et al., 1999; Braver and Cohen, 2001). The successful exertion of cognitive control is thus, accomplished via the PFC's exertion of top-down control on the posterior and subcortical brain regions involved in task-specific processing based on online goal representations (Miller and Cohen, 2001; Tamber-Rosenau et al., 2011). The IPFC is credited with not just the storage and maintenance of contextual representations in a highly accessible format, but also with the biasing of other, posterior cortical regions involved in task-specific processes, such as action selection and memory retrieval (Braver and Cohen, 2001; Braver et al., 2007). The concerted activity of the PFC and areas such as the anterior cingulate cortex (ACC), involved in interference detection; the posterior cortex, involved in the selective processing of sensory information and storage of domain-specific knowledge; and medial temporal lobe (MTL) structures, involved in associative binding and memory consolidation, enable the production of context-specific, goal-relevant behavior (Braver and Cohen, 2001).
The structural and functional deterioration of the PFC in older adults is indeed one of the most consistently reported findings in aging research (Cabeza, 2002; Raz et al., 2005; Ziegler et al., 2012). In older adults, the diminished ability for top-down modulation of irrelevant information is reflected by a general pattern of enhanced cortical activation in frontal regions (Cabeza, 2002; Grady et al., 2002; Colcombe et al., 2005; Prakash et al., 2009). On tasks of cognitive control, for example, older adults, relative to young, demonstrate cortical overactivation in areas of the taskpositive, cognitive control network (CCN), comprised of dorsolateral prefrontal cortex (dlPFC), inferior parietal cortex, and supplementary motor area (Reuter-Lorenz et al., 2000; Cabeza, 2002; Cabeza et al., 2004). Moreover, older adults show a failure to modulate neural activity in these areas in response to increased task demands (Reuter-Lorenz and Mikels, 2006; Prakash et al., 2009), suggesting a general deficiency and inflexibility in the utilization of PFC-based cognitive control resources (Reuter-Lorenz and Park, 2010).

Accompanying the general over-recruitment of the PFC in aging, is the reduction in recruitment of the posterior processing regions (Davis et al., 2008), which could be indicative of a compensatory strategy of cortical recruitment. Alternatively, this could be reasonably reframed as being associated with an early disruption in goal maintenance, resulting in a failure to appropriately activate associative-sensory posterior regions in preparation for organized action. In addition to age-related shifts in the patterns of local brain activity and connectivity associated with cognitive control, there is also evidence for the utilization of a temporally-lagged, late-onset strategy in older adults during controlled cognitive processing, such that older adults show a failure to engage top-down attentional sets during early stages of a memory retrieval process, along with an increased recruitment of PFC regions during later stages (Velanova et al., 2007). Taken together, these neuroimaging studies provide collective support for the alteration in the spatial and temporal activity of the lateral prefrontal cortices, known to broadly serve cognitive control, and specifically the capacity to engage in goal-relevant task representations (Figure 1).

In fact, in a direct test of the goal-maintenance account, Paxton et al. (2008) examined the neural activity in the IPFC in older, relative to young adults during a modified version of the Continuous Performance Test (AX-CPT). Utilizing a combination of contextual, goal-relevant cues that demand maintenance of proactive control and ambiguous probes that require the re-activation of task-sets, thus eliciting reactive control, the task was designed to parse out the age-related variance in the recruitment of the IPFC during these two separate cognitive control strategies. Interestingly, while older adults showed sustained over-recruitment of the IPFC during the task, activity associated with goal maintenance during cue-related trials was diminished. These results were interpreted to suggest that aging is characterized by a shift in cognitive control strategies, such that older adults move from a more proactive cognitive control strategy which enables early selection of task-appropriate stimuli to a reactive control strategy which could either result in a temporally protracted response or a failure to inhibit taskirrelevant representations. 
In further support of the goal-maintenance account, Gamboz et al. (2010) found age-related reductions primarily in the alerting component of the Attention Network Task (ANT; Fan et al., 2002). Usually employing some variant of the response compatibility paradigm, the ANT differentiates attention into three inter-related functions of alerting, orienting, and conflict resolution (Posner and Petersen, 1990). The alerting component taps into the ability to maintain an alert and stable taskstate, presumably also invoking a representation of goals and task-related instructions. The evidence for an age-related decline in this component provides further support for the account that it is the maintenance of a vigilant, goal-relevant state that is compromised in older adults. Thus, a training program designed to increase moment-to-moment attention would be beneficial in enhancing cognitive control. Interestingly, in this study Gamboz et al. (2010) did not find evidence for an agerelated reduction in the executive control component of the ANT contrary to many previously published studies reporting significant reductions in the ability to resolve response competition in older adults (Nielson et al., 2002; Colcombe et al., 2005).

One possible explanation for the discrepant findings in the executive control literature might have to do with the impact of perceptual load on the processing of goal relevant information (Lavie, 2005, 2010). According to the load theory of attention and cognitive control, the processing of irrelevant information or distractors is critically dependent on the perceptual load of the stimuli, such that higher perceptual load eliminates distractor interference, and low perceptual load can enhance the processing of irrelevant information, thereby increasing distractor interference (Lavie, 1995; Lavie and Cox, 1997). In fact, the extent to which tasks of low perceptual load result in distractor interference is further contingent on the frontal lobe capacities of individuals, such that older adults with compromised prefrontal cortex functioning show evidence of greater distractor interference than young adults at low perceptual loads (Maylor and Lavie, 1998). Thus, both perceptual load and executive load combined together can explain the mixed results of the cognitive aging literature and provide contextual evidence for a decline in executive control abilities in older adults.

To summarize, cognitive control capacities involving the meticulous and sustained recruitment of the IPFC are compromised in older adults, with deficits in goal maintenance lying at the crux of such cognitive control capacities. Training programs designed to specifically target enhancement of specific cognitive control abilities show limited transfer effects, presumably because of an inability to enhance moment-to-moment attentional control and simultaneously reduce distractions from internal and external disruptions. In addition, much of the training literature thus far is restricted by its failure to tap into the unique socioemotional motives which guide the behavior of older adults, therefore, such studies suffer from limited transfer effects. In order to determine whether a training program that enhances emotional well-being is circuitously able to influence the interrelated processes of cognitive control, the study of mindfulness in the elderly is crucial.

\section{EMOTIONAL PROCESSING AND AGING}

The study of cognitive control in aging has been historically divorced from research focusing on the developmental trajectory of emotion processing and regulation in older adults. While unidimensional decline models of aging have been at the forefront of gerontological research, providing evidence for physical, physiological, and cognitive decline in the elderly, research in the field of emotional processing points to enhanced emotional wellbeing and satisfaction in older age (for a review see Charles and Carstensen, 2010 and see Figure 1 for a summary of the key findings). Despite having smaller social networks (Fung et al., 2001, 2008; Yeung et al., 2008), older adults report experiencing greater overall satisfaction and more positive than negative emotions in their social networks, relative to young adults (Carstensen, 1992; Newsom et al., 2005; Charles and Piazza, 2007).

Embedded within the construct of enhanced emotional wellbeing in older adults is their affinity towards positive rather than negative information, whether remembering real-life situations or stimuli in a laboratory-based task. When recalling the past, older adults tend to remember it more favorably than young adults (Kennedy et al., 2004). This age-related preference is observed even when remembering negative life events (Comblain et al., 2005), such that older adults give higher positive ratings of negative events, relative to the young cohort. Higher recall of positively-valenced laboratory stimuli has now been reported in several studies, and this shift from a predilection for negative information in young adulthood (Rozin and Royzman, 2001) to a heightened processing of positive stimuli, and reduced processing of negative information in older adulthood has been referred to as the "positivity effect" (Mather and Carstensen, 2003; Mikels et al., 2005). The positivity effect has been observed across a widerange of laboratory-based tasks using a diverse array of emotional stimuli, and has been used to substantiate the hypothesis that aging is characterized by a greater preference for materials and attributes that are more positive than negative (e.g., Charles et al., 2003; Leigland et al., 2004; Mikels et al., 2005; Piguet et al., 2008; Shamaskin et al., 2010).

While a few theoretical accounts have been suggested for these findings, the socioemotional selectivity theory proposed by Carstensen et al. remains the dominant lens of interpretation (Carstensen, 1993, 2006; Carstensen et al., 1999; Reed and Carstensen, 2012). According to this theoretical model, a key developmental change that accounts for older adults' acquired preference for positive over negative information is the change in goal orientation and motivation induced by the perceived narrowing of one's scope of time as the temporal unfolding of life proceeds. With aging comes the inevitable realization of a limited time left in life, and thus, goals of emotional satisfaction and well-being take precedence over the future-oriented goals of achievement and self-expansion which most of young adulthood is geared toward. This shift in priorities, thus, leads to an increased focus on those attributes of life events and stimuli that would likely serve the higher-order, chronically-activated goals associated with ensuring well-being (Knight et al., 2007). Driven by these motivations and priorities, older adults, thus, selectively attend to positive stimuli and divert their attention away from negative information (Isaacowitz et al., 2006); are better able to 
positively appraise and dwell less on negative information than young adults (Charles and Carstensen, 2008); and engage in behaviors and emotion regulation strategies that support positive affect (Lefkowitz and Fingerman, 2003; Story et al., 2007; Löckenhoff and Carstensen, 2008).

To the extent that such selective preference is governed by adaptive higher-order goals related to emotional well-being, much of this age-related predilection appears to be under the influence of controlled regulatory processing. It may indeed be the case that cognitive control is a necessary pre-requisite for the successful implementation of the positivity effect (Mather and Carstensen, 2005; Kryla-Lighthall and Mather, 2009). In fact, research provides support for the positivity effect being a byproduct of conscious, top-down regulatory processing, rather than being driven by more automatic, bottom-up processing. Individual differences in levels of cognitive capacity in older adults have been found to be associated with the tendency to favor positive pictures during memory recall (Mather and Knight, 2005). And interestingly, the preference for positive over negative pictures declines, once cognitive resources are directed to another task (Mather and Knight, 2005). More evidence for the delayed, conscious processing of positive over negative information comes from event-related potential studies that examine the temporal response to positive and neutral stimuli in older, relative to young adults (Williams et al., 2006; Isaacowitz et al., 2009). These studies suggest that the positivity effect is not present during rapidly presented emotionally salient stimuli, and when the effect is observed, it emerges much later after stimulus presentation, rather than directly following the onset of attention towards the positive stimuli.

The notion that the ability to successfully reappraise negative events is dependent on conscious cognitive control is further substantiated by the neuroimaging literature which consistently provides evidence for the enhanced engagement of the top-down neural circuitry of the prefrontal cortices in older adults during processing and reappraisal of affective stimuli (Urry et al., 2006; Williams et al., 2006; Leclerc and Kensinger, 2011). It is well known now that the neural circuitry of emotional processing involves key regions of the frontal cortex, specifically the ventromedial prefrontal cortex (vmPFC) and the dlPFC, as well as subcortical structures such as the amygdala and other association cortices (Phillips et al., 2003; Ochsner and Gross, 2008). The established structural and functional connections between this frontal-based, top-down network and subcortical bottom-up processing system represent the integrated neural infrastructure through which emotional responses are generated, coordinated, and modulated based on the allocation of cognitive resources (Ochsner et al., 2002, 2004). A failure in either system, resulting in either an amplification of the emotional cue's saliency, via the activity of the amygdala or a failure to appropriately dampen emotional reactivity, through decreased top-down prefrontal activation may be sufficient to impede the successful deployment of emotional control (Rosenkranz et al., 2003; Goldin et al., 2008).

Research studies examining age-related differences in these neural regions supporting emotional processing now provide evidence for a three-way interaction between age, valence, and neural region (Gutchess et al., 2007; Ritchey et al., 2011; for a review, see Samanez-Larkin and Carstensen, 2011). While older adults demonstrate an up-regulation of the dlPFC and the vmPFC during negative, compared to positive pictures (Leclerc and Kensinger, 2011), they show an up-regulation in the amygdala during positive, relative to negative stimuli (Mather et al., 2004). Specifically, accumulating evidence suggests that even in the absence of instructed emotional regulation, older adults engage in spontaneous emotional regulation, reflected by reduced amygdala activation, coupled with increased recruitment of the frontal cortex, particularly in the medial and lateral areas of the prefrontal cortex, during the perception of negative emotional stimuli (Mather et al., 2004). However, when participants are instructed to engage in explicit emotional regulation, the findings are more mixed and seem to vary according to the strategies engaged by the task instructions. That is, older adults are more successful at regulating aversive affective stimuli when asked to engage in positive reappraisal and attentional deployment (Shiota and Levenson, 2009), rather than detached reappraisal (Winecoff et al., 2011). Further, when controlling for attentional deployment effects, older adults are less successful at using cognitive control to reappraise the negative stimuli than young adults (Opitz et al., 2012), despite a relatively greater frequency of engaging in cognitive reappraisal strategies (John and Gross, 2004).

Collectively, older adults do pay more attention to positive than negative stimuli and use certain selective emotional regulation strategies more effectively than others (Urry and Gross, 2010). While some of these age-related findings can be attributed to an increased reliance on structures of the prefrontal cortex that decline less structurally, such as the vmPFC (Raz, 2000; Fjell et al., 2009) and the ACC, the increased top-down neural recruitment of the dIPFC, despite its deteriorating capacity to maintain positive affect and decrease the influence of negative attributes, is consistent with the increased emphasis on emotional well-being in older adults (Mather, 2012). Another recent finding by Brassen et al. (2012) reporting reduced regret in emotionally healthy older adults following conditions of a decision task that elicited regret, suggests that one possible mechanism through which older adults might enhance emotional regulation is through the up- and down-regulation of positive affect (Suri and Gross, 2012). A training program designed to increase controlled regulatory processing in the elderly would, thus, need to tap into older adults' higher-ordinate goals concerning emotional well-being and increased life-satisfaction. In the next section of this review article, we discuss the various facets of mindfulness training, with a special emphasis on the role of such training in enhancing emotional control and increasing overall life satisfaction.

\section{MINDFULNESS TRAINING AND CONTROLLED REGULATORY PROCESSING}

Interest in the construct of mindfulness has been gaining increasing momentum in the scientific world. Stemming from an interest in health and overall well-being, the study of mindfulness goes beyond the treatment of symptoms of psychopathology, which has historically dominated clinical science research. Individual 
differences in dispositional mindfulness or the cultivation of mindfulness skills through formal practices are now being systematically investigated to better understand the impact of this construct on individuals' emotional and cognitive well-being (Brown and Ryan, 2003; de Vibe et al., 2012), physical health (Kabat-Zinn, 1982; Kabat-Zinn et al., 1985; Ludwig and KabatZinn, 2008), immunological functioning (Davidson et al., 2003; Creswell et al., 2012), and overall quality of life (Nyklícek and Kuijpers, 2008; Krygier et al., 2013).

Embedded in the Buddhist tradition, the term "mindfulness" is one of the elements of the noble eightfold path articulated in the teachings of the Buddha (Bodhi, 2011). The complexities of this construct, as it was originally intended in the teachings of the Buddha have, until today, intrigued and perplexed Buddhist scholars. Therefore, much of the literature reviewed and presented here, stems from the contemporary definition of mindfulness that was first articulated by Jon Kabat-Zinn (1990, 2003).

Mindfulness, as defined in the contemporary sciences, is the practice of purposefully directing attention and in a nonjudgmental way observing the unfolding of each moment as it takes place (Kabat-Zinn, 1994). The key facets of this concept involve a conscious choice to engage in the present-moment in its absolute entirety; bring an element of one-focused concentrative attention to the object(s) of the present-moment; and take the perspective of an impartial witness to the constantly changing cascade of thoughts, sensations, feelings, and other events. Importantly, it is critical that while performing all such activities, one does so by using the attitudinal principles of nonjudgment, trust, patience, acceptance, non-striving, letting-go, and beginner's mind (Kabat-Zinn, 1990).

While a number of meditation practices support the cultivation of the principles of mindfulness, focused attention and open monitoring are considered to be at the heart of many traditional 8 week mindfulness-based stress reduction (MBSR) programs (Lutz et al., 2007; Holzel et al., 2011). Utilizing the ever-present breath as an anchor, the practice of focused attention cultivates the development of sustained attention on the in- and out-flow of the breath. In the process of doing so, the goal of breath awareness practice is to stabilize the habitual, reflexive patterns of the wandering mind. These practices are hypothesized to enhance attentional control, and by learning to observe the natural process of the breath and extending this exercise to an entire array of experiences through the practice of open monitoring, the technique of mindful observation has been shown to enhance emotional regulation (Arch and Craske, 2006; Chambers et al., 2009; Farb et al., 2010). In fact, many recent models of mindfulness training conceptualize increased attentional control and emotional regulation as key mechanisms amongst others that support the cultivation of mindfulness (see Vago and Silbersweig, 2012 for an excellent review and theoretical conceptualization of the study of mindfulness).

Contextualizing the limited efficacy of current training paradigms in improving cognitive control in the elderly within the framework of the shifting socioemotional motivations associated with older adults' capacity for enhanced emotional processing, we hypothesize that a training program that simultaneously targets cognitive and emotional control and their neurobiological substrates would be more likely to successfully improve the overall quality of life in older adults. Mindfulness, as will be shown in this section, strengthens the neural circuitry associated with emotional and cognitive control. In addition, it has been shown to enhance the integrity of a critical resting-state system, the default-mode network, which underlies the functionality of these two inter-related networks. From this standpoint, the study of mindfulness appears to be uniquely capable of modifying not only the neuroarchitecture associated with controlled regulatory processing, but also the elementary infrastructure on which the brain's baseline functioning is contingent (Figure 2).

\section{MINDFULNESS AND EMOTION REGULATION}

Emotion regulation, refers to the change in the subjective experience of emotion, including the temporal context in which it is experienced as well as the intensity and behavioral expression of that emotion (Gross, 1998). This individual capacity has important implications for decision-making, social functioning, psychopathological development, homeostatic processes, and overall quality of life.

Mindfulness, involving an attitudinal orientation of curiosity, openness, and acceptance, has been linked to emotional intelligence in its shared focus on perceptual clarity to one's emotional state (Salovey and Mayer, 1990). A number of studies have in fact attributed the efficacy of mindfulness in reducing symptoms of stress and negative affect to its capacity to modify emotion regulation abilities (Arch and Craske, 2006; Chambers et al., 2008, 2009), with evidence suggesting that emotion regulation is directly engaged during the active performance of mindful exercises (Ortner et al., 2007; Farb et al., 2010). By enhancing behavioral self-regulation (Lykins and Baer, 2009), increasing emotional differentiation (Hill and Updegraff, 2012), and reducing the routine tendency to emotionally react to transitory thoughts and physical sensations (Teasdale et al., 2000; Ramel et al., 2004), mindfulness practice is thought to decrease negative affect, stress, and mood disturbance (Brown and Ryan, 2003), and protect against symptoms of anxiety and depression (Ostafin et al., 2006), including ruminative thinking (Jain et al., 2007; Deyo et al., 2009). In fact, core components of mindfulness have been integrated into clinical usage in therapeutic models ranging from Dialectical Behavioral Therapy (Linehan, 1994) to Mindfulness-Based Cognitive Therapy (Segal et al., 2002).

While there is unequivocal evidence for the role of mindfulness in enhancing overall emotional well-being and its associated facets, an interesting perspective, debating the involvement of bottom-up versus top-down neural control systems, has emerged in the neuroscientific study of mindfulness and emotional regulation (Chiesa et al., 2013). Much of this literature is in its relative infancy, and the heterogeneity of the adopted methods makes it slightly challenging to draw inferences and conclusions across studies. However, this diversity in methodology across various studies provides a platform upon which to evaluate the neural correlates of mindfulness in a number of different contexts. These include cross-sectional studies which examine it as a dispositional variable; short-term mindfulness training studies which 


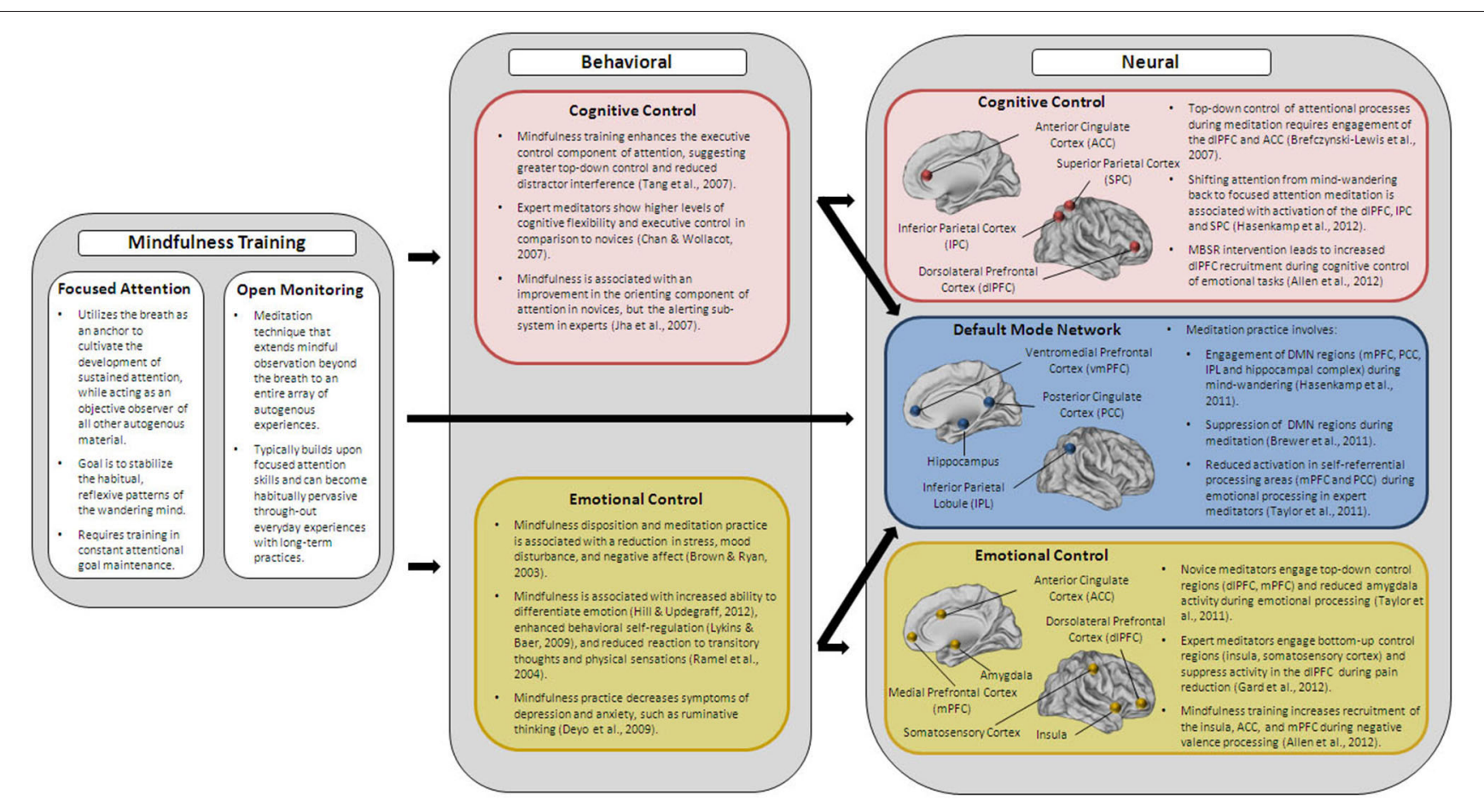

FIGURE 2 | Summarizes the key behavioral and neural findings of the effects of mindfulness training on cognitive and emotional control.

aim to teach the skills of mindfulness to community-participants; as well as case studies of expert meditators, whose long-term practice of concentrative attention and open monitoring provide insights into the brain's potential for neural plasticity following such intense mindful exercises. While comparing such varied studies can be fraught with its own set of challenges, including fluidity with the very definition of mindfulness (Grossman, 2011; Awasthi, 2013), such a comparison can also enable us to better understand the qualitative differences that might emerge based on the particular nature of meditative practice a given individual engages in. A critical question involves understanding what, if any, differential effect is observed when examining the impact of mindfulness on a novice practitioner who engages in this practice for 30-50 h of training, as is standard in a traditional mindfulness-based training program, versus an advanced practitioner who approaches mindfulness more as a value system and lifestyle, rather than a temporally-isolated experience in a training program.

Indeed, an examination of the association between mindfulness and the neural correlates of emotion regulation provides evidence for the recruitment of separate, yet inter-related processes of bottom-up and top-down emotional control in experts of mindfulness, relative to the short-term practitioners of mindfulness. Taylor et al. (2011) examined individual responses to emotional and neutral pictures from the International Affective Picture System (Lang et al., 1997) in a group of Zen meditators with experience of greater than $1000 \mathrm{~h}$ as compared to a group of novices. Participants were presented with these pictures during rest as well as during a condition that instructed them to engage in concentrative attention practice by making the breath as their anchor. Across participants, the mindfulness condition was associated with a decrease in emotional intensity, but the neural regions supporting such decreased emotional response were found to differ between experienced and novice practitioners. Specifically, novice practitioners were found to reduce activity in the bilateral amygdalae when processing negative or positive pictures, relative to the neutral stimuli, suggesting a down-regulation of this sub-cortical region during instructions of concentrative focus. Interestingly, the contrast of emotionallyintense stimuli with the neutral stimuli did not result in an up-regulation of the prefrontal cortices, as would be expected if processes of top-down control were activated. However, collapsing across valence categories indicated that novice, but not experienced meditators, showed an increased activation of the right $\mathrm{dlPFC}$ and the right posterior cingulate cortex (PCC) during the mindful condition. In here, the authors did not report a direct contrast between the novices versus the experienced meditators, so while these findings are preliminary and require replication, an intriguing possibility is that novice mediators might be engaging in emotional control through an upregulation of the top-down control systems. Additionally, the study also reported that experienced meditators demonstrated a reduction in activity of the $\mathrm{mPFC}$ and the PCC across all valence categories, suggesting that a reduction in self-referential processing areas, rather than a reduced engagement of processes serving cognitive reappraisal, supports reduction in emotional reactivity in expert meditators. Further support for the engagement of the top-down circuitry during emotional experiences in 
controls is provided by studies of pain perception (Grant and Rainville, 2009; Grant et al., 2011; Gard et al., 2012). In such studies, control participants were able to reduce pain unpleasantness via the recruitment of the lateral prefrontal cortices, while expert meditators were found to successfully regulate the perception of pain through the recruitment of regions supporting viscero-somatic awareness, such as the posterior insula and the somatosensory cortex, and suppression of the activity of the dlPFC.

Complementary MRI research involving short-term mindfulness training programs (Allen et al., 2012) and studies of dispositional mindfulness as a trait variable (Creswell et al., 2007) also show evidence supporting the hypothesis that the engagement of cognitive reappraisal strategies underlies the reduction in emotional reactivity following a short-term training. In one such study, Creswell et al. (2007) examined the association between dispositional mindfulness and neural regions involved during an affect labeling task. They reported higher levels of dispositional mindfulness to be associated with increased recruitment of the dlPFC and reduced activity of the amygdala during labeling of affective stimuli, as compared to gender labeling. These results relating the construct of dispositional mindfulness with greater top-down involvement during the viewing of affective stimuli has been replicated in several other studies (Frewen et al., 2010; Modinos et al., 2010). These results provide support for the hypothesis that qualitative differences in the impact of mindfulness exist when this construct is treated as an idiosyncratic characteristic that varies in individuals ranging everywhere from community participants to expert meditators well-versed in practices of concentrative attention and open monitoring.

Similarly, short-term mindfulness-based studies also provide evidence for such engagement of the prefrontal cortices during affective regulation following limited training in principles and practices of mindfulness. In a recent study, Allen et al. (2012) examined alterations in neural recruitment during an emotional Stroop task in a group of participants that were randomized to a 6 week mindfulness training program, relative to participants in an active control group. Interestingly, post-intervention, participants in the mindfulness group showed enhanced recruitment of the dlPFC during executive processing, supporting the involvement of top-down control regions in short-term practitioners of mindfulness. Increased recruitment in the right anterior insula, ACC, as well as the mPFC during negative valence processing was observed only for individuals reporting greater engagement with the practices of mindfulness.

These studies collectively support a theoretical model of mindfulness and emotional regulation that offers the possibility of increased top-down regulation of the prefrontal cortices on the sub-cortical structures supporting emotional reactivity to increase emotional regulation in the early stages of mindfulness training. It seems likely that even though mindfulness training appears to be theoretically divergent from training that involves explicit cognitive appraisal, short-term training in this approach may in fact be associated with the engagement of systems supporting conscious cognitive regulation of affective experiences. With increased exercise of mindfulness skills and consistent engagement in consciously controlled emotion regulation, the practice of open monitoring, likely becomes habitual and pervasive. This shift, thereby enables an engagement of the neural circuitry supporting interoceptive awareness and somatosensory representation. For future research, it would be interesting to examine if a qualitative shift in the practice of mindfulness in novice participants is accompanied by a shift in reliance on the top-down regions to ones supporting sensory awareness.

\section{MINDFULNESS AND COGNITIVE CONTROL}

At the crux of the construct of mindfulness lies its promotion of single-minded goal maintenance in the face of external or internal interference. The study of cognitive control, thus as an outcome variable has garnered critical interest in mindfulnessrelated research (Jha et al., 2007; Xiong and Doraiswamy, 2009; Chiesa et al., 2011; Malinowski, 2013). Both behavioral and neuroimaging studies, employing numerous variants of cognitive control tasks, have sought to determine whether training in mindfulness abilities, involving concentrative attention and open monitoring, are indeed associated with (1) an enhanced capacity to maintain a task-vigilant alert state, in which distractions arising from internal representations are prevented from interfering with task-set maintenance or task performance, and (2) better performance on tasks of executive control which require resolution of response competition through reduced interference from goalirrelevant, external stimuli. As noted earlier, goal-neglect errors and related differences in working memory capacity during cognitive control performance have been suggested to stem in part from momentary failures of conscious thought control (Kane and Engle, 2003). Thus, mindfulness training might be theorized to directly relate to the controlled-attention component (i.e., the goal-maintenance component of the cognitive control of working memory), the successful functioning of which is thought to directly support executive control abilities and reduce response interference.

One of the widely used tasks in the mindfulness literature is the ANT, and as noted earlier, this task helps differentiate between three inter-related components or subsystems of attention: alerting, orienting, and executive control. The training of mindfulness skills has been found to enhance the executive control component of attention (Tang et al., 2007; Zeidan et al., 2010). This suggests that short-term training in skills of mindfulness can indeed enhance the ability to engage the topdown attentional control system and reduce distractor interference. Expert meditators, when compared to novices, have also been found to perform better on tasks tapping into response competition, such that sustained practices of focused attention result in higher levels of cognitive flexibility and executive control (Chan and Woollacott, 2007; Moore and Malinowski, 2009; van den Hurk et al., 2010a). Complementary neuroimaging evidence also provides support for the engagement of the PFC and the ACC during tasks of executive control, suggesting the further involvement of the neural circuitry sub-serving top-down cognitive control operations during the practice of mindfulness (Brefczynski-Lewis et al., 2007; Tang and Posner, 2009). 
In addition to the malleability of the executive control component, research also provides support for the enhanced functioning of the alerting sub-system in expert meditators, relative to novices. The long-term cultivation of mindfulness, thus enhances the capacity to maintain a constant state of alertness, resulting in increased moment-to-moment awareness and thereby increasing the capacity for sustained attention (Lutz et al., 2008, 2009; Moore and Malinowski, 2009). In fact, extensive training with meditation practices was also found to counter the effects of an age-related decline in sustained attention in a group of Zen meditators (Pagnoni and Cekic, 2007), suggesting that such practices might be prophylactic for the decline in sustained attention or the alerting component of attention observed in the elderly (Gamboz et al., 2010).

Interestingly, mapping the emotional regulation literature, there appears to be some consistent differences surfacing between the techniques of expert practitioners, relative to individuals having undergone brief mindfulness-related programs. In the first direct test of these differences, Jha et al. (2007) compared performance on the ANT task between a group of meditationnaïve participants who engaged in a traditional 8 week MBSR program and a group of expert meditators who engaged in a 1 month intensive mindfulness retreat program, practicing the meditative skills for $10-12 \mathrm{~h}$ a day. While participation in the MBSR program enhanced the orienting skills of the participants, the expert meditators showed better performance on the alerting sub-component of the ANT task following the retreat, compared to participants in the MBSR group. Additionally, prior meditation experience was found to be correlated with the alerting subcomponent, such that greater years of meditation practice was associated with better performance on this sub-component of attention. The results of this study provide first support for the hypothesis that a brief training program can engage the top-down attentional control system, thus improving aspects of voluntary attentional control. It also suggests that long-term engagement, resulting in the cultivation of a mindful state, is associated with the habitual promotion of sustained cognitive focus; possibly mediated through a reduction of distractions from goalirrelevant representations and responses, arising both externally and internally.

Mirroring these behavioral findings, Brewer et al. (2011) found a differential engagement of the regions of the default-mode network in expert meditators, relative to novices, as they engaged in various meditation techniques. In this study, the authors examined the engagement of a critical network of the brain that has now been implicated in several functions, prominently including self-referential processing (Andrews-Hanna et al., 2007, 2010) and in mind-wandering during tasks of focused attention (Mason et al., 2007). The serendipitous discovery of the default-mode network as a task-negative network (Shulman et al., 1997; Raichle et al., 2001) that demonstrates deactivation during performance on tasks that require cognitive control operations has provided us with great insights into the functional architecture of the intrinsic networks of the brain and their coherence during exogenous and endogenous processing (Buckner et al., 2008; Biswal et al., 2010). The description of the default-mode network as the task-negative network of the brain stems primarily from its negative correlation with the CCN that is often engaged during tasks of response competition (Fox et al., 2005; Hagmann et al., 2008; Buckner et al., 2009; Cole et al., 2010). The activation of regions of the default-mode network during studies of attentional control has been found to be associated with poor performance (Shulman et al., 2007; Anticevic et al., 2010), mind-wandering (Mason et al., 2007; Christoff et al., 2009), task-irrelevant thoughts (McKiernan et al., 2003, 2006; Stawarczyk et al., 2011), and maladaptive ruminative thinking (Hamilton et al., 2011). In fact, recently Smallwood et al. (2013) found that mind wandering, indexed by trials preceding errors on a task of cognitive control, was associated with activation of the regions of the default-mode network. Given that neural activity prior to committing an error likely represents a lapse in attentional control, the activation of the regions comprising the default-mode network suggest the engagement of these regions when attention is diverted from the current context to inward processing.

Corroborating this involvement of the default-mode network regions, specifically the $\mathrm{mPFC}$, as well as the PCC during mind-wandering, Brewer et al. (2011) found support for the suppression of neural activity in these regions in expert meditators when engaged in different meditation practices, relative to demographically-matched controls. That is, by continuously exercising the selective direction of attention, long-term practitioners of mindfulness were able to appropriately modulate task-relevant and irrelevant regions, thereby strengthening the integrity of the various intrinsic networks. The engagement of the default-mode network during mind-wandering in meditators was further substantiated in another recent study by Hasenkamp et al. (2012) which examined the neural correlates of four stages of a cognitive cycle. These included, the presence of mind-wandering, the awareness that mind-wandering has indeed taken place, the shifting of attention to the present moment, and finally the maintenance of attention. Mind-wandering in expert meditators, was found to engage the PCC, the mPFC, the posterior parietal/temporal cortex, and the parahippocampal gyrus, all nodes of the defaut-mode network (DMN). Sustained attention and the shifting of attention were, in fact, associated with the activity of the dlPFC and the parietal cortices, thus, corroborating previous research on the fronto-parietal network and its involvement in sustaining attention.

While still preliminary and needing replication, these studies suggest that brief mindfulness training programs that cultivate both focused attention and open monitoring allow the development of enhanced cognitive control operations. This is thought to take place primarily through the engagement of the top-down cognitive control system, with the frontal and parietal cortices being critically involved in the selection of task-relevant attributes and suppression of task-irrelevant attributes (Figure 2). Longterm engagement in the practices of focused attention, and subsequent open monitoring via receptive attention to the plethora of events unfolding on a moment-to-moment basis creates a state of preparedness and alertness by fundamentally reducing vulnerability to the everyday reactivity and distractions of the wandering mind (Bishop et al., 2004). The result is a more flexible modulation of neural networks supporting various stages of an attentional state and the subsequent strengthening of these 
critical networks. Taken together, the training of mindfulness skills appears to have the potential to influence the inter-related circuitry of the cognitive control network, as well as the defaultmode network. Given the deficits seen in the recruitment and suppression of both these networks in older adults per the demands of the task (Prakash et al., 2009, 2012), mindfulness training may be a viable solution for the deficits in cognitive control seen in older adults. By reducing the distractions arising from external stimuli, as well as internal disruptions, long-term training with mindfulness can, in fact, result in a task-dependent modulation of the critical networks of the brain, which may enhance cognitive performance and likely reduce rumination.

\section{FUTURE DIRECTIONS AND KEY CONSIDERATIONS}

The above-reviewed literature provides support for the potential of mindfulness training in improving controlled regulatory processing. By virtue of enhancing one-minded concentration and sustained attention, mindfulness training gradually cultivates the development of attentional skills that promote goal maintenance, while reducing distractions not just from external, competing stimuli, but also from the internal disruptions and wanderings of the mind (Mrazek et al., 2012, 2013). In so doing, mindfulness qualitatively enhances our ability to engage in more conscious top-down cognitive control through the recruitment of the IPFC, gradually promoting a state of vigilance and sustained attention that may be extended to all objects of attention. The result of years of such concentrative attention seems to be a shift from reliance on the prefrontal cortices, known to be critically involved in consciously controlled top-down attentional control, to a more bottom-up recruitment of the viscero-somatic regions supporting a flexible modulation of the intrinsic networks of the human brain (van den Hurk et al., 2010b; Josipovic et al., 2012). Extending this to the domain of emotional regulation, mindfulness training has the potential to enhance overall wellbeing, primarily by engaging conscious awareness at every level of each action and perception in the present moments, eventually resulting in a reduced tendency to behave reflexively. Teaching individuals to cultivate an openness to the experiences of the present moment, by taking the stance of an impartial witness, mindfulness training specifically promotes the development of emotion regulation rather than emotional reactivity. Older adults, with their predilection to engage in effortful emotional regulation, are thus, likely to benefit from a training program that purports to further enhance and strengthen their skills of emotional regulation, and in the process of doing so, also improve the facets of cognitive control that decline with aging. Thus, a critical direction for future research is to examine if mindfulness training is in fact associated with increases in emotional regulation and

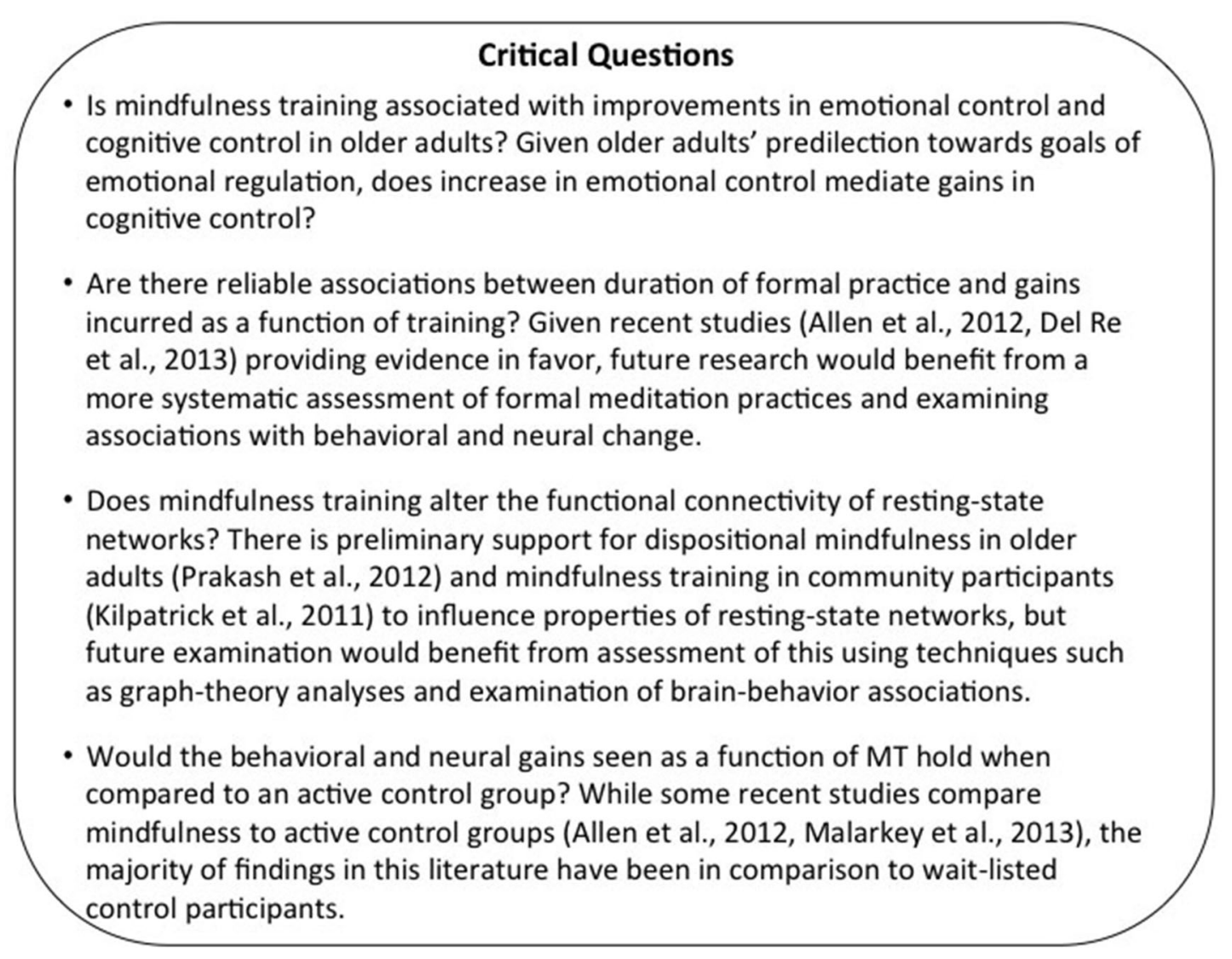

FIGURE 3 | Highlights the key points from the section on Future Directions and Key Considerations. 
cognitive control in older adults (see Figure 3 for key directions for future research). Evidence for the efficacy of this low-cost intervention in incurring broad gains in cognitive and emotional functioning would contribute significantly to the field of cognitive aging.

This area of research has further been strengthened by the growing contributions of neuroimaging studies aiming to examine the contributions of cortical and sub-cortical regions in cognitive and emotional control. The involvement of the IPFC in both emotional and cognitive control suggests the possibility of neural overlap in these two inter-dependent processes. This, in turn, has the potential to predict functional overlap, which is associated with broad transfer effects (Lustig et al., 2009). Previous studies of cognitive training have, in fact, provided evidence for the possibility of broad transfer effects to functional tasks when neural overlap was present between the trained task and the transfer task. In such a study, Dahlin et al. (2008) found evidence for transfer of training in young adults, and not older adults, primarily due to the absence of shared neural recruitment between the trained task (memory updating) and the transfer task (working memory) in older adults. The authors concluded that it was the reliance on a shared neural circuitry that was critical for the presence of broad transfer effects. Given the shared circuitry of emotional and cognitive control in older adults, mindfulness training, by virtue of enhancing emotional control, also has the potential to increase cognitive performance. Of course, an interesting line of future research would be the examination of whether it is the increase in emotion regulation capabilities that fosters greater cognitive control or the development of cognitive control capacity that is a necessary pre-requisite for increased emotional regulation? Research has just started to answer this question of a temporal evolution of cognitive and emotional control capacities in the context of mindfulness practices (Sahdra et al., 2011), with studies providing preliminary evidence supporting cognitive control capacities as precursors to the development of enhanced emotional regulation. However, it would be important to examine the relative change in emotional and cognitive control capacities in an aging population that places greater emphasis on emotional regulation skills. It would be interesting in future research to systematically examine the evolution of enhanced cognitive and emotional capacity in both an older and young cohort in order to systematically differentiate the effect of mindfulness training on these inter-related capacities as a function of age.

Another critical theme that emerges from the above reviewed literature is the presence of qualitative differences in neural engagement in long-term practitioners of mindfulness, relative to short-term practitioners of the techniques. Transliterating these findings to the study of mindfulness, it is critical for future studies to systematically examine the amount of time spent by participants engaging in the formal practice of mindfulness during the 8 week period. Short-term training studies that have investigated the association between time spent in formal practice and psychological and neural benefits evince support for the critical variance explained by engaging in such formal practices of concentrative attention and open monitoring (Allen et al., 2012; Del Re et al., 2013). While novice meditators tend to recruit more of the top-down circuitry of the lateral prefrontal cortices, expert meditators and those engaging in greater amounts of practice in an 8 week program show evidence for the involvement of the viscero-somatic regions of the somatosensory cortices, insular cortices, and regions of the default-mode network.

Interestingly, in our own research, we have found evidence for an association between higher levels of dispositional mindfulness and connectivity of the default-mode network in older adults (Prakash et al., 2013). In this study, participants completed a self-report measure of mindfulness disposition (Mindful Attention and Awareness Scale, MAAS; Brown and Ryan, 2003) and completed a resting-state scan. Network integrity was examined in the default-mode network, given recent investigations of the involvement of this network in self-referential processing and its associated negative correlations with the cognitive control network. Higher levels of mindfulness disposition in older adults were found to be associated with connectivity of the dorsal PCC, such that the increased connectivity of this area with the rest of the default-mode network provided evidence for greater neuronal integrity of this area with the DMN. Interestingly, the dorsal PCC has been implicated more as a switch area that works at the interface of the cognitive control and default-mode networks (Leech et al., 2011). The involvement of this area, relative to the ventral PCC which is often implicated in the traditional default-mode network, provides evidence suggesting that mindfulness disposition may be associated with the flexible modulation of neuronal regions. Future work would need to examine the extent to which the findings of a cross-sectional study mirror the results of a short-term training program, as recent conceptualizations of mindfulness would suggest qualitative differences between examining this construct as a trait measure versus examining it as an acquired skill honed through the practice of concentrative attention and a non-judgmental attitude.

Finally, keeping in perspective the growing interest in intervention studies that "train the brain", it is critical to examine the efficacy of mindfulness training, relative to an active control group, that reduces participant bias and accounts for the amount of time spent by participants engaging in activities related to the program. While these threats to internal validity of a randomized controlled trial have been well-known for a while (Campbell and Stanley, 1963; Shadish et al., 2002), much of the training literature (and not just the mindfulness literature) tends to ignore the possible influence of participant motivation on task performance (see Boot et al., 2011; Boot and Simons, 2012 for a critical discussion of this issue). While it is our position that wait-listed studies provide a critical cost-effective, pragmatic approach to generating hypotheses about the outcome and the mechanisms underlying a training approach, investigative efforts moving forward need to examine the effects of mindfulness interventions, relative to more active control programs.

The unique capacity for flexible, consciously-controlled, dynamic behavior distinguishes the human species from all others, providing us with the seeds of adaptability and creativity and granting us a communicable sense of free will and a degree of control over the environment. In the current work, we 
present a comprehensive review of how cognitive and emotional control change, behaviorally and neurally, as a function of age and examine how a mindfulness-based model may have the potential to counteract such nuanced age-related alterations in controlled regulatory processing. It is hoped that the comprehensive review provided in this paper may be somehow used to guide future investigations of emotion-cognition processes in the elderly. By developing more refined methods of examining agerelated changes in cognitive, affective, and neural functioning, we move closer towards understanding the complex metamorphosis of the aging brain and our powerful role in relationship to it.

\section{REFERENCES}

Allen, M., Dietz, M., Blair, K. S., van Beek, M., Rees, G., Vestergaard-Poulsen, P., et al. (2012). Cognitive-affective neural plasticity following active-controlled mindfulness intervention. J. Neurosci. 32, 15601-15610. doi: 10.1523/jneurosci. 2957-12.2012

Andrews-Hanna, J. R., Reidler, J. S., Huang, C., and Buckner, R. L. (2010). Evidence for the default network's role in spontaneous cognition. J. Neurophysiol. 104, 322-335. doi: 10.1152/jn.00830.2009

Andrews-Hanna, J. R., Snyder, A. Z., Vincent, J. L., Lustig, C., Head, D., Raichle, M. E., et al. (2007). Disruption of large-scale brain systems in advanced aging. Neuron 56, 924-935. doi: 10.1016/j.neuron.2007.10.038

Anticevic, A., Repovs, G., Shulman, G. L., and Barch, D. M. (2010). When less is more: TPJ and default network deactivation during encoding predicts working memory performance. Neuroimage 49, 2638-2648. doi: 10.1016/j.neuroimage. 2009.11.008

Arch, J. J., and Craske, M. G. (2006). Mechanisms of mindfulness: emotion regulation following a focused breathing induction. Behav. Res. Ther. 44, 18491858. doi: 10.1016/j.brat.2005.12.007

Awasthi, B. (2013). Issues and perspectives in meditation research: in search for a definition. Front. Psychol. 3:613. doi: 10.3389/fpsyg.2012.00613

Bishop, S., Lau, M., Shapiro, S., Carlson, L., Anderson, N., Carmody, J., et al. (2004). Mindfulness: a proposed operational definition. Clin. Psychol. Sci. Practice 11, 230-241. doi: 10.1093/clipsy.bph077

Biswal, B. B., Mennes, M., Zuo, X. N., Gohel, S., Kelly, C., Smith, S. M., et al. (2010). Towards discovery science of human brain function. Proc. Natl. Acad. Sci. U S A 107, 4734-4739. doi: 10.1073/pnas.0911855107

Bodhi, B. (2011). What does mindfulness really mean? A canonical perspective. Contemp. Buddhism 12, 19-39. doi: 10.1080/14639947.2011.564813

Boot, W. R., Blakely, D. P., and Simons, D. J. (2011). Do action video games improve perception and cognition? Front. Psychol. 2:226. doi: 10.3389/fpsyg.2011. 00226

Boot, W. R., and Simons, D. J. (2012). Advances in video game methods and reporting practices (but still room for improvement): a commentary on Strobach, Frensch and Schubert (2012). Acta Psychol. (Amst) 141, 276-277. doi: 10.1016/j. actpsy.2012.06.011

Brassen, S., Gamer, M., Peters, J., Gluth, S., and Büchel, C. (2012). Don't look back in anger! Responsiveness to missed chances in successful and nonsuccessful aging. Science 336, 612-614. doi: 10.1126/science.1217516

Braver, T. S., and Barch, D. M. (2002). A theory of cognitive control, aging cognition and neuromodulation. Neurosci. Biobehav. Rev. 26, 809-817. doi: 10. 1016/s0149-7634(02)00067-2

Braver, T. S., and Cohen, J. D. (2001). Working memory, cognitive control and the prefrontal cortex: computational and empirical studies. Cogn. Process. 2, 25-55.

Braver, T. S., Gray, J. R., and Burgess, G. C. (2007). "Explaining the many varieties of working memory variation: dual mechanisms of cognitive control," in Variation in Working Memory, eds A. R. A. Conway, C. Jarrold, M. J. Kane, A. Miyake and J. N. Towse (New York, NY: Oxford University Press), 76-106.

Braver, T. S., Satpute, A. B., Rush, B. K., Racine, C. A., and Barch, D. M. (2005). Context processing and context maintenance in healthy aging and early-stage dementia of the Alzheimer's type. Psychol. Aging 20, 33-46. doi: 10.1037/08827974.20.1.33
Braver, T. S., and West, R. F. (2008). "Working memory, executive control and aging," in The Handbook of Aging and Cognition, eds F. I. M. Craik and T. A. Salthouse (New York, NY: Psychology Press), 311-372.

Brefczynski-Lewis, J. A., Lutz, A., Schaefer, H. S., Levinson, D. B., and Davidson, R. J. (2007). Neural correlates of attentional expertise in long-term meditation practitioners. Proc. Natl. Acad. Sci. U S A 104, 11483-11488. doi: 10.1073/pnas. 0606552104

Brewer, J. A., Worhunsky, P. D., Gray, J. R., Tang, Y. Y., Weber, J., and Kober, H. (2011). Meditation experience is associated with differences in default mode network activity and connectivity. Proc. Natl. Acad. Sci. U S A 108, 20254-20259. doi: 10.1073/pnas.1112029108

Brown, K. W., and Ryan, R. M. (2003). The benefits of being present: mindfulness and its role in psychological well-being. J. Pers. Soc. Psychol. 84, 822-848. doi: 10. 1037/0022-3514.84.4.822

Buckner, R. L., Andrews-Hanna, J. R., and Schacter, D. L. (2008). The brain's default network: anatomy, function and relevance to disease. Ann. N Y Acad. Sci. 1124, 1-38. doi: 10.1196/annals.1440.011

Buckner, R. L., Sepulcre, J., Talukdar, T., Krienen, F. M., Liu, H., Hedden, T., et al. (2009). Cortical hubs revealed by intrinsic functional connectivity: mapping, assessment of stability and relation to Alzheimer's disease. J. Neurosci. 29, 1860 1873. doi: 10.1523/jneurosci.5062-08.2009

Cabeza, R. (2002). Hemispheric asymmetry reduction in old adults: the HAROLD model. Psychol. Aging 17, 85-100. doi: 10.1037/0882-7974.17.1.85

Cabeza, R., Daselaar, S. M., Dolcos, F., Prince, S. E., Budde, M., and Nyberg, L. (2004). Task-independent and task-specific age effects on brain activity during working memory, visual attention and episodic retrieval. Cereb. Cortex 14, 364 375. doi: 10.1093/cercor/bhg133

Campbell, D. T., and Stanley, J. C. (1963). Experimental and Quasi-Experimental Designs for Research. Boston, MA: Houghton Mifflin Company.

Carstensen, L. L. (1992). Social and emotional patterns in adulthood: support for socioemotional selectivity theory. Psychol. Aging 7, 331-338. doi: 10.1037/08827974.7.3.331

Carstensen, L. L. (1993). Motivation for social contact across the life span: a theory of socioemotional selectivity. Nebr. Symp. Motiv. 40, 209-254.

Carstensen, L. L. (2006). The influence of a sense of time on human development. Science 312, 1913-1915. doi: 10.1126/science.1127488

Carstensen, L. L., Isaacowitz, D. M., and Charles, S. T. (1999). Taking time seriously: a theory of socioemotional selectivity. Am. Psychol. 54, 165-181. doi: 10. 1037/0003-066x.54.3.165

Carstensen, L. L., Pasupathi, M., Mayr, U., and Nesselroade, J. R. (2000). Emotional experience in everyday life across the adult life span. J. Pers. Soc. Psychol. 79, 644655. doi: 10.1037/0022-3514.79.4.644

Chambers, R., Gullone, E., and Allen, N. B. (2009). Mindful emotion regulation: an integrative review. Clin. Psychol. Rev. 29, 560-572. doi: 10.1016/j.cpr.2009. 06.005

Chambers, R., Lo, B. C. Y., and Allen, N. B. (2008). The impact of intensive mindfulness training on attentional control, cognitive style and affect. Cognit. Ther. Res. 32, 303-322. doi: 10.1007/s10608-007-9119-0

Chan, D., and Woollacott, M. (2007). Effects of level of meditation experience on attentional focus: is the efficiency of executive or orientation networks improved? J. Altern. Complement. Med. 13, 651-657. doi: 10.1089/acm.2007. 7022

Charles, S. T. (2010). Strength and vulnerability integration: a model of emotional well-being across adulthood. Psychol. Bull. 136, 1068-1091. doi: 10. 1037/a0021232

Charles, S. T., and Carstensen, L. L. (2008). Unpleasant situations elicit different emotional responses in younger and older adults. Psychol. Aging 23, 495-504. doi: $10.1037 / \mathrm{a} 0013284$

Charles, S. T., and Carstensen, L. L. (2010). Social and emotional aging. Annu. Rev. Psychol. 61, 383-409. doi: 10.1146/annurev.psych.093008.100448

Charles, S. T., Mather, M., and Carstensen, L. L. (2003). Aging and emotional memory: the forgettable nature of negative images for older adults. J. Exp. Psychol. Gen. 132, 310-324. doi: 10.1037/0096-3445.132.2.310

Charles, S. T., and Piazza, J. R. (2007). Memories of social interactions: age differences in emotional intensity. Psychol. Aging 22, 300-309. doi: 10.1037/08827974.22.2.300

Chiesa, A., Calati, R., and Serretti, A. (2011). Does mindfulness training improve cognitive abilities? A systematic review of neuropsychological findings. Clin. Psychol. Rev. 31, 449-464. doi: 10.1016/j.cpr.2010.11.003 
Chiesa, A., Serretti, A., and Jakobsen, J. C. (2013). Mindfulness: top-down or bottom-up emotion regulation strategy? Clin. Psychol. Rev. 33, 82-96. doi: 10. 1016/j.cpr.2012.10.006

Christoff, K., Gordon, A. M., Smallwood, J., Smith, R., and Schooler, J. W. (2009). Experience sampling during fMRI reveals default network and executive system contributions to mind wandering. Proc. Natl. Acad. Sci. U S A 106, 8719-8724. doi: 10.1073/pnas.0900234106

Colcombe, S. J., Kramer, A. F., Erickson, K. I., and Scalf, P. (2005). The implications of cortical recruitment and brain morphology for individual differences in inhibitory function in aging humans. Psychol. Aging 20, 363-375. doi: 10. 1037/0882-7974.20.3.363

Cole, M. W., Pathak, S., and Schneider, W. (2010). Identifying the brain's most globally connected regions. Neuroimage 49, 3132-3148. doi: 10.1016/j.neuroimage. 2009.11.001

Comblain, C., D'Argembeau, A., and Van Der Linden, M. (2005). Phenomenal characteristics of autobiographical memories for emotional and neutral events in older and younger adults. Exp. Aging Res. 31, 173-189. doi: 10. 1080/03610730590915010

Creswell, J. D., Irwin, M. R., Burklund, L. J., Lieberman, M. D., Arevalo, J. M., Ma, J., et al. (2012). Mindfulness-based stress reduction training reduces loneliness and pro-inflammatory gene expression in older adults: a small randomized controlled trial. Brain Behav. Immun. 26, 1095-1101. doi: 10.1016/j.bbi.2012. 07.006

Creswell, J. D., Way, B. A., Eisenberger, N. I., and Lieberman, M. D. (2007). Neural correlates of dispositional mindfulness during affect labeling. Psychosom. Med. 69, 560-565. doi: 10.1097/psy.0b013e3180f6171f

Dahlin, E., Neely, A. S., Larsson, A., Backman, L., and Nyberg, L. (2008). Transfer of learning after updating training mediated by the striatum. Science 320, 1510 1512. doi: $10.1126 /$ science. 1155466

Davidson, R. J. (2010). Empirical explorations of mindfulness: conceptual and methodological conundrums. Emotion 10, 8-11. doi: 10.1037/a00 18480

Davidson, R. J., Kabat-Zinn, J., Schumacher, J., Rosenkranz, M., Muller, D., Santorelli, S. F., et al. (2003). Alterations in brain and immune-function produced by mindfulness meditation. Psychosom. Med. 65, 564-570. doi: 10 . 1097/01.PSY.0000077505.67574.E3

Davis, S. W., Dennis, N. A., Daselaar, S. M., Fleck, M. S., and Cabeza, R. (2008). Que PASA? The posterior-anterior shift in aging. Cereb. Cortex 18, 1201-1209. doi: 10.1093/cercor/bhm155

De Jong, R. (2001). Adult age differences in goal activation and goal maintenance. Eur. J. Cogn. Psychol. 13, 71-89. doi: 10.1080/09541440126238

de Vibe, M., Bjørndal, A., Tipton, E., Hammerstrom, K., and Kowalski, K. (2012). Mindfulness based stress reduction (MBSR) for improving health, quality of life and social functioning in adults. Campbell Syst. Rev. 3, 1-127. doi: 10.4073/csr. 2012.3

Del Re, A. C., Flückiger, C., Goldberg, S. B., and Hoyt, W. T. (2013). Monitoring mindfulness practice quality: an important consideration in mindfulness practice. Psychother. Res. 23, 54-66. doi: 10.1080/10503307.2012.72 9275

Deyo, M., Wilson, K. A., Ong, J., and Koopman, C. (2009). Mindfulness and rumination: does mindfulness training lead to reduction in the ruminative thinking associated with depression? Explore (NY) 5, 265-271. doi: 10.1016/j. explore.2009.06.005

Dunlosky, J., Kubat-Silman, A. K., and Hertzog, C. (2003). Training monitoring skills improves older adults' self-paced associative learning. Psychol. Aging 18, 340-345. doi: 10.1037/0882-7974.18.2.340

Fan, J., McCandliss, B. D., Sommer, T., Raz, A., and Posner, M. I. (2002). Testing the efficiency and independence of attentional networks. J. Cogn. Neurosci. 14, 340-347. doi: 10.1162/089892902317361886

Farb, N. A. S., Anderson, A. K., Mayberg, H. S., Bean, J., McKeon, D., and Segal, Z. V. (2010). Minding one's emotions: mindfulness training alters the neural expression of sadness. Emotion 10, 25-33. doi: 10.1037/a0017151

Fjell, A. M., Westlye, L. T., Amlien, I., Espeseth, T., Reinvang, I., Raz, N., et al. (2009). High consistency of regional cortical thinning in aging across multiple samples. Cereb. Cortex 19, 2001-2012. doi: 10.1093/cercor/bhn232

Fox, M. D., Snyder, A. Z., Vincent, J. L., Corbetta, M., Van Essen, D. C., and Raichle, M. E. (2005). The human brain is intrinsically organized into dynamic, anticorrelated functional networks. Proc. Natl. Acad. Sci. U S A 102, 9673-9678. doi: $10.1073 /$ pnas. 0504136102
Frewen, P. A., Dozois, D. J. A., Neufeld, R. W. J., Lane, R. D., Densmore, M., Stevens, T. K., et al. (2010). Individual differences in trait mindfulness predict dorsomedial prefrontal and amygdala response during emotional imagery: an fMRI study. Pers. Individ. Dif. 49, 479-484. doi: 10.1016/j.paid.2010. 05.008

Fried, L. P., Carlson, M. C., Freedman, M., Frick, K. D., Glass, T. A., Hill, J., et al. (2004). A social model for health promotion for an aging population: initial evidence on the experience corps model. J. Urban Health 81, 64-78. doi: 10. 1093/jurban/jth094

Fung, H. H., Carstensen, L. L., and Lang, F. R. (2001). Age-related patterns in social networks among European Americans and African Americans: implications for socioemotional selectivity across the life span. Int. J. Aging Hum. Dev. 52, 185206. doi: 10.2190/1abl-9be5-m0x2-lr9v

Fung, H. H., Lu, A. Y., Goren, D., Isaacowitz, D. M., Wadlinger, H. A., and Wilson, H. R. (2008). Age-related positivity enhancement is not universal: older Chinese look away from positive stimuli. Psychol. Aging 23, 440-446. doi: 10.1037/08827974.23.2.440

Gamboz, N., Zamarian, S., and Cavallero, C. (2010). Age-related differences in the attention network test (ANT). Exp. Aging Res. 36, 287-305. doi: 10. 1080/0361073X.2010.484729

Gard, T., Hölzel, B. K., Sack, A. T., Hempel, H., Lazar, S. W., Vaitl, D., et al. (2012). Pain attenuation through mindfulness is associated with decreased cognitive control and increased sensory processing in the brain. Cereb. Cortex 22, 26922702. doi: $10.1093 /$ cercor/bhr352

Gavrilov, L. A., and Heuveline, P. (2003). “Aging of population,” in The Encyclopedia of Population, eds P. Demeny and G. McNicoll (New York, NY: Macmillan Reference USA), 32-37.

Gazzaley, A. (2013). “Top-down modulation effect in the aging brain: an emerging theory of cognitive aging," in Stuss, DT, Knight, RT, eds D. T. Stuss and R. T. Knight, 2nd Edn. (New York: Oxford Press), 593-608.

Gazzaley, A., Cooney, J. W., Rissman, J., and D'Esposito, M. (2005). Top-down suppression deficit underlies working memory impairment in normal aging. Nat. Neurosci. 8, 1298-1300. doi: 10.1038/nn1205-1791c

Goh, J. O., An, Y., and Resnick, S. M. (2012). Differential trajectories of age-related changes in components of executive and memory processes. Psychol. Aging 27, 707-719. doi: 10.1037/a0026715

Goldin, P. R., McRae, K., Ramel, W., and Gross, J. J. (2008). The neural bases of emotion regulation: reappraisal and suppression of negative emotion. Biol. Psychiatry 63, 577-586. doi: 10.1016/j.biopsych.2007.05.031

Grady, C. L., Bernstein, L., Siegenthaler, A., and Beig, S. (2002). The effects of encoding task on age-related differences in the functional neuroanatomy of face memory. Psychol. Aging 17, 7-23. doi: 10.1037//0882-7974. 17.1.7

Grant, J. A., Courtemanche, J., and Rainville, P. (2011). A non-elaborative mental stance and decoupling of executive and pain-related cortices predicts low pain sensitivity in Zen meditators. Pain 152, 150-156. doi: 10.1016/j.pain.2010. 10.006

Grant, J. A., and Rainville, P. (2009). Pain sensitivity and analgesic effects of mindful states in Zen meditators: a cross-sectional study. Psychosom. Med. 71, 106-114. doi: 10.1097/psy.0b013e31818f52ee

Gross, J. J. (1998). Antecedent and response-focused emotion regulation: divergent consequences for experience, expression and physiology. J. Pers. Soc. Psychol. 74, 224-237. doi: 10.1037//0022-3514.74.1.224

Grossman, P. (2011). Defining mindfulness by how poorly I think I pay attention during everyday awareness and other intractable problems for psychology's (re)invention of mindfulness: comment on Brown et al. (2011). Psychol. Assess. 23, 1034-1040. doi: 10.1037/a0022713

Gutchess, A. H., Kensinger, E. A., and Schacter, D. L. (2007). Aging, selfreferencing and medial prefrontal cortex. Soc. Neurosci. 2, 117-133. doi: 10. 1080/17470910701399029

Hagmann, P., Cammoun, L., Gigandet, X., Meuli, R., Honey, C. J., Weeden, V. J., et al. (2008). Mapping the structural core of human cerebral cortex. PLoS Biol. 6:e159. doi: 10.1371/journal.pbio.0060159

Hamilton, J. P., Furman, D. J., Chang, C., Thomason, M. E., Dennis, E., and Gotlib, I. H. (2011). Default-mode and task-positive network activity in major depressive disorder: implications for adaptive and maladaptive rumination. Biol. Psychiatry 70, 327-333. doi: 10.1016/j.biopsych.2011.02.003

Hasenkamp, W., Wilson-Mendenhall, C. D., Duncan, E., and Barsalou, L. W. (2012). Mind wandering and attention during focused meditation: a 
fine-grained temporal analysis of fluctuating cognitive states. Neuroimage 59, 750-760. doi: 10.1016/j.neuroimage.2011.07.008

Hasher, L., and Zacks, R. T. (1988). Working memory, comprehension and aging: a review and a new view. Psychol. Learn. Motiv. 22, 193-225. doi: 10.1016/s00797421(08)60041-9

Hay, E. L., and Diehl, M. (2011). Emotion complexity and emotion regulation across adulthood. Eur. J. Ageing 8, 157-168. doi: 10.1007/s10433-0110191-7

Hertzog, C., Kramer, A. F., Wilson, R. S., and Lindenberger, U. (2009). Enrichment effects on adult cognitive development: can the functional capacity of older adults be preserved and enhanced? Psychol. Sci. Public Interest 9, 1-65. doi: 10. $1111 / j .1539-6053.2009 .01034 . x$

Hill, C. L., and Updegraff, J. A. (2012). Mindfulness and its relationship to emotional regulation. Emotion 12, 81-90. doi: 10.1037/a0026355

Holzel, B. K., Lazar, S. W., Gard, T., Schuman-Olivier, Z., Vago, D. R., and Ott, U. (2011). How does mindfulness meditation work? Proposing mechanisms of action from a conceptual and neural perspective. Perspect. Psychol. Sci. 6, 537559. doi: $10.1177 / 1745691611419671$

Isaacowitz, D. M., Allard, E. S., Murphy, N. A., and Schlanger, M. (2009). The time course of age-related preferences toward positive and negative stimuli. J. Gerontol. B Psychol. Sci. Soc. Sci. 64B, 188-192. doi: 10.1093/geronb/ gbn036

Isaacowitz, D. M., Wadlinger, H. A., Goren, D., and Wilson, H. R. (2006). Selective preference in visual fixation away from negative images in old age? An eyetracking study. Psychol. Aging 21, 40-48. doi: 10.1037/0882-7974.21.2.221

Jain, S., Shapiro, S., Swanick, S., Roesch, S. C., Mills, P. J., Bell, I., et al. (2007). A randomized controlled trial of mindfulness meditation versus relaxation training: effects on distress, positive states of mind, rumination and distraction. Ann. Behav. Med. 33, 11-21. doi: 10.1207/s15324796abm3301_2

Jha, A. P., Kromponger, J., and Baime, M. J. (2007). Mindfulness training modifies subsystems of attention. Cogn. Affect. Behav. Neurosci. 7, 109-119. doi: 10. 3758/cabn.7.2.109

John, O. P., and Gross, J. J. (2004). Healthy and unhealthy emotion regulation: personality processes, individual differences and lifespan development. J. Pers. 72, 1301-1334. doi: 10.1111/j.1467-6494.2004.00298.x

Josipovic, Z., Dinstein, I., Weber, J., and Heeger, D. J. (2012). Influence of meditation on anti-correlated networks in the brain. Front. Hum. Neurosci. 5:183. doi: 10.3389 /fnhum.2011.00183

Kabat-Zinn, J. (1982). An outpatient program in behavioral medicine for chronic pain patients based on the practice of mindfulness meditation: theoretical considerations and preliminary results. Gen. Hosp. Psychiatry 4, 33-47. doi: 10. 1016/0163-8343(82)90026-3

Kabat-Zinn, J. (1990). Full Catastrophe Living. New York, NY: Bantam Dell.

Kabat-Zinn, J. (1994). Wherever You Go, There You Are: Mindfulness Meditation in Everyday Life. New York, NY: Hyperion.

Kabat-Zinn, J. (2003). Mindfulness-based interventions in context: past, present and future. Clin. Psychol. Sci. Practice 10, 144-156. doi: 10.1093/clipsy. bpg016

Kabat-Zinn, J., Lipworth, L., and Burney, R. (1985). The clinical use of mindfulness meditation for the self-regulation of chronic pain. J. Behav. Med. 8, 163-190. doi: $10.1007 / \mathrm{bf} 00845519$

Kane, M. J., and Engle, R. W. (2003). Working-memory capacity and the control of attention: the contributions of goal neglect, response competition and task set to Stroop interference. J. Exp. Psychol. Gen. 132, 47-70. doi: 10.1037/0096-3445. 132.1.47

Kennedy, Q., Mather, M., and Carstensen, L. L. (2004). The role of motivation in the age-related positivity effect in autobiographical memory. Psychol. Sci. 15, 208-214. doi: 10.1111/j.0956-7976.2004.01503011.x

Kilpatrick, L. A., Suyenobu, B. Y., Smith, S. R., Bueller, J. A., Goodman, T., Creswell, J. D., et al. (2011). Impact of mindfulness-based stress reduction training on intrinsic brain connectivity. Neuroimage 56, 290-298. doi: 10.1016/j. neuroimage.2011.02.034

Knight, M., Seymour, T. L., Guant, J. T., Baker, C., Nesmith, K., and Mather, M. (2007). Aging and goal-directed emotional attention: distraction reverses emotional biases. Emotion 7, 705-714. doi: 10.1037/1528-3542.7.4.705

Krygier, J. R., Heathers, J. A., Shahrestani, S., Abbott, M., Gross, J. J., and Kemp, A. H. (2013). Mindfulness meditation, well-being and heart rate variability: a preliminary investigation into the impact of intensive Vipassana meditation. Int. J. Psychophysiol. 89, 305-313. doi: 10.1016/j.ijpsycho.2013.06.017
Kryla-Lighthall, N., and Mather, M. (2009). "The role of cognitive control in older adults' emotional well-being," in Handbook of Theories of Aging, eds V. Berngston, D. Gans, N. Putney and M. Silverstein (New York, NY: Springer Publishing), 323-344.

Lang, P. J., Bradley, M. M., and Cuthbert, B. N. (1997). International Affective Picture System (IAPS): Technical Manual and Affective Ratings. Gainesville, FL: National Institute of Mental Health Center for the Study of Emotion and Attention.

Lavie, N. (1995). Perceptual load as a necessary condition for selective attention. J. Exp. Psychol. Hum. Percept. Perform. 21, 451-468. doi: 10.1037//0096-1523.21. 3.451

Lavie, N. (2005). Distracted and confused?: selective attention under load. Trends Cogn. Sci. 9, 75-82. doi: 10.1016/j.tics.2004.12.004

Lavie, N. (2010). Attention, distraction and cognitive control under load. Curr. Dir. Psychol. Sci. 19, 143-148. doi: 10.1177/0963721410370295

Lavie, N., and Cox, S. (1997). On the efficiency of attentional selection: efficient visual search results in inefficient rejection of distraction. Psychol. Sci. 8, 395398. doi: 10.1111/j.1467-9280.1997.tb00432.x

Leclerc, C. M., and Kensinger, E. A. (2011). Neural processing of emotional pictures and words: a comparison of young and older adults. Dev. Neuropsychol. 36, 519538. doi: 10.1080/87565641.2010.549864

Leech, R., Kamourieh, S., Beckmann, C. F., and Sharp, D. J. (2011). Fractionating the default mode network: distinct contributions of the ventral and dorsal posterior cingulate cortex to cognitive control. J. Neurosci. 31, 3217-3224. doi: 10.1523/jneurosci.5626-10.2011

Lefkowitz, E. S., and Fingerman, K. L. (2003). Positive and negative emotional feelings and behaviors in mother-daughter ties in late life. J. Fam. Psychol. 17, 607-617. doi: 10.1037/0893-3200.17.4.607

Leigland, L. A., Schulz, L. E., and Janowsky, J. S. (2004). Age related changes in emotional memory. Neurobiol. Aging 25, 1117-1124. doi: 10.1016/j.neurobiolaging. 2003.10.015

Linehan, M. M. (1994). "Acceptance and change: the central dialectic in psychotherapy," in Acceptance and Change: Content and Context in Psychotherapy, eds S. C. Hayes, N. S. Jacobson, V. M. Follette and M. J. Dougher (Reno, NV: Context Press), 73-86.

Löckenhoff, C. E., and Carstensen, L. L. (2008). Decision strategies in health care choices for self and others: older but not younger adults make adjustments for the age of the decision target. J. Gerontol. B Psychol. Sci. Soc. Sci. 63, P106-P109. doi: 10.1093/geronb/63.2.p106

Ludwig, D. S., and Kabat-Zinn, J. (2008). Mindfulness in medicine. JAMA 300, 1350-1352. doi: 10.1001/jama.300.11.1350

Lustig, C., Shah, P., Seidle, R., and Reuter-Lorenz, P. (2009). Aging, training and the brain: a review and future directions. Neuropsychol. Rev. 19, 504-522. doi: 10. 1007/s11065-009-9119-9

Lutz, A., Dunne, J. P., and Davidson, R. J. (2007). "Meditation and the neuroscience of consciousness: an introduction," in The Cambridge Handbook of Consciousness, eds P. D. Zelazo, M. Moscovitch and E. Thompson (New York, NY: Cambridge University Press), 499-551.

Lutz, A., Greischar, L. L., Rawlings, N. B., Ricard, M., and Davidson, R. J. (2009). Mental training enhances attentional stability: neural and behavioral evidence. J. Neurosci. 29, 13418-13427. doi: 10.1523/jneurosci.1614-09.2009

Lutz, A., Slagter, H. A., Dunne, J. D., and Davidson, R. J. (2008). Attention regulation and monitoring in meditation. Trends Cogn. Sci. 12, 163-169. doi: 10. 1016/j.tics.2008.01.005

Lykins, E. L. B., and Baer, R. A. (2009). Psychological functioning in a sample of long-term practitioners of mindfulness meditation. J. Cogn. Psychother. 23, 226241. doi: $10.1891 / 0889-8391.23 .3 .226$

Malinowski, P. (2013). Natural mechanisms of attentional control in mindfulness meditation. Front. Neurosci. 7:8. doi: 10.3389/fnins.2013.00008

Mason, M. F., Norton, M. I., Van Horn, J. D., Wegner, D. M., Grafton, S. T., and Macrae, C. N. (2007). Wandering minds: the default network and stimulusindependent thought. Science 315, 393-395. doi: 10.1126/science.1131295

Mather, M. (2012). The emotion paradox in the aging brain. Ann. N Y Acad. Sci. 1251, 33-49. doi: 10.1111/j.1749-6632.2012.06471.x

Mather, M., and Carstensen, L. L. (2003). Aging and attentional biases for emotional faces. Psychol. Sci. 14, 409-415. doi: 10.1111/1467-9280.01455

Mather, M., and Carstensen, L. L. (2005). Aging and motivated cognition: the positivity effect in attention and memory. Trends Cogn. Sci. 9, 496-502. doi: 10. 1016/j.tics.2005.08.005 
Mather, M., Canli, T., English, T., Whitfield, S., Wais, P., Ochsner, K., et al. (2004). Amygdala responses to emotionally valenced stimuli in older and younger adults. Psychol. Sci. 15, 259-263. doi: 10.1111/j.0956-7976.2004. 00662.x

Mather, M., and Knight, M. (2005). Goal-directed memory: the role of cognitive control in older adults' emotional memory. Psychol. Aging 20, 554-570. doi: 10. 1037/0882-7974.20.4.554

Maylor, E., and Lavie, N. (1998). The influence of perceptual load on age differences in selective attention. Psychol. Aging 13, 563-573. doi: 10.1037//0882-7974.13. 4.563

McKiernan, K. A., D’Angelo, B. R., Kaufman, J. N., and Binder, J. R. (2006). Interrupting the "stream of consciousness": an fMRI investigation. Neuroimage 29, 1185-1191. doi: 10.1016/j.neuroimage.2005.09.030

McKiernan, K. A., Kaufman, J. N., Kucera-Thompson, J., and Binder, J. R. (2003). A parametric manipulation of factors affecting task-induced deactivation in functional neuroimaging. J. Cogn. Neurosci. 15, 394-408. doi: 10. 1162/089892903321593117

Mikels, J. A., Larkin, G. R., Reuter-Lorenz, P. A., and Carstensen, L. L. (2005). Divergent trajectories in the aging mind: changes in working memory for affective versus visual information with age. Psychol. Aging 20, 542-553. doi: 10. 1037/0882-7974.20.4.542

Miller, E. K., and Cohen, J. D. (2001). An integrative theory of prefrontal cortex function. Annu. Rev. Neurosci. 24, 167-202. doi: 10.1146/annurev.neuro.24. 1.167

Modinos, G., Ormel, J., and Aleman, A. (2010). Individual differences in dispositional mindfulness and brain activity involved in reappraisal of emotion. Soc. Cogn. Affect. Neurosci. 5, 369-377. doi: 10.1093/scan/nsq006

Moore, A., and Malinowski, P. (2009). Meditation, mindfulness and cognitive flexibility. Conscious. Cogn. 18, 176-186. doi: 10.1016/j.concog.2008. 12.008

Mrazek, M. D., Franklin, M. S., Philips, D. T., Baird, B., and Schooler, J. W. (2013). Mindfulness training improves working memory capacity and GRE performance while reducing mind wandering. Psychol. Sci. 24, 776-781. doi: 10. $1177 / 0956797612459659$

Mrazek, M. D., Smallwood, J., and Schooler, J. W. (2012). Mindfulness and mindwandering: finding convergence through opposing constructs. Emotion 12, 442448. doi: 10.1037/a0026678

Newsom, J. T., Rooks, K. S., Nishishiba, M., Sorkin, D. H., and Mahan, T. L. (2005). Understanding the relative importance of positive and negative social exchanges: examining specific domains and appraisals. J. Gerontol. B Psychol. Sci. Soc. Sci. 60, P304-P312. doi: 10.1093/geronb/60.6.p304

Nielson, K. A., Langenecker, S. A., and Garavan, H. (2002). Differences in the functional neuroanatomy of inhibitory control across the adult life span. Psychol. Aging 17, 56-71. doi: 10.1037//0882-7974.17.1.56

Noice, H., Noice, T., and Staines, G. (2004). A short-term intervention to enhance cognitive and affective functioning in older adults. J. Aging Health 16, 562-585. doi: 10.1177/0898264304265819

Nyklícek, I., and Kuijpers, K. F. (2008). Effects of mindfulness-based stress reduction intervention on psychological well-being and quality of life: is increased mindfulness indeed the mechanism? Ann. Behav. Med. 35, 331-340. doi: 10. 1007/s12160-008-9030-2

Ochsner, K. N., Bunge, S. A., Gross, J. J., and Gabrieli, J. D. E. (2002). Rethinking feelings: an fMRI study of the cognitive regulation of emotion. J. Cogn. Neurosci. 14, 1215-1299. doi: 10.1162/089892902760807212

Ochsner, K. N., and Gross, J. J. (2008). Cognitive emotion regulation: insights from social cognitive and affective neuroscience. Curr. Dir. Psychol. Sci. 17, 153-158. doi: 10.1111/j.1467-8721.2008.00566.x

Ochsner, K. N., Ray, R. D., Cooper, J. C., Robertson, E. R., Chopra, S., Gabrieli, J. D., et al. (2004). For better or for worse: neural systems supporting the cognitive down- and- up- regulation of negative emotion. Neuroimage 23, 483499. doi: 10.1016/j.neuroimage.2004.06.030

Opitz, P. C., Rauch, L. C., Terry, D. P., and Urry, H. L. (2012). Prefrontal mediation of age differences in cognitive reappraisal. Neurobiol. Aging 33, 645-655. doi: 10. 1016/j.neurobiolaging.2010.06.004

O’Reilly, R. C., Braver, T. S., and Cohen, J. D. (1999). “A biologically-based computational model of working memory," in Models of Working Memory: Mechanisms of Active Maintenance and Executive Control, eds A. Miyake and P. Shah (New York, NY: Cambridge University Press), 375-411.
Ortner, C. N. M., Kilner, S. J., and Zelazo, P. D. (2007). Mindfulness meditation and reduced emotional interference on a cognitive task. Motiv. Emot. 31, 271283. doi: 10.1007/s11031-007-9076-7

Ostafin, B. D., Chawla, N., Bowen, S., Dillworth, T. M., Witkiewitz, K., and Marlatt, G. A. (2006). Intensive mindfulness training and the reduction of psychological distress: a preliminary study. Cogn. Behav. Pract. 13, 238-239. doi: 10.1016/j. cbpra.2005.12.002

Pagnoni, G., and Cekic, M. (2007). Age effects on gray matter volume and attentional performance in Zen meditation. Neurobiol. Aging 28, 1623-1627. doi: 10.1016/j.neurobiolaging.2007.06.008

Park, D. C., and Bischof, G. N. (2013). The aging mind: neuroplasticity in response to cognitive training. Dialogues Clin. Neurosci. 15, 109-119. doi: 10.1016/b9780-12-380882-0.00007-3

Park, D. C., and Reuter-Lorenz, P. (2009). The adaptive brain: aging and neurocognitive scaffolding. Annu. Rev. Psychol. 60, 173-196. doi: 10.1146/annurev.psych. 59.103006.093656

Park, D. C., Lautenschlager, G., Hedden, T., Davidson, N. S., Smith, A. D., and Smith, P. K. (2002). Models of visuospatial and verbal memory across the adult life span. Psychol. Aging 17, 299-320. doi: 10.1037/0882-7974.17. 2.299

Park, D. C., Lodi-Smith, J., Drew, L., Haber, S., Hebrank, A., Bischof, G. N., et al. (2014). The impact of sustained engagement on cognitive function in older adults: the synapse project. Psychol. Sci. 25, 103-112. doi: 10.1177/ 0956797613499592

Paxton, J. L., Barch, D. M., Racine, C. A., and Braver, T. S. (2008). Cognitive control, goal maintenance and prefrontal function in healthy aging. Cereb. Cortex 18 , 1010-1028. doi: 10.1093/cercor/bhm135

Phillips, M. L., Drevets, W. C., Rauch, S. L., and Lane, R. (2003). Neurobiology of emotion perception I: the neural basis of normal emotional perception. Biol. Psychiatry 54, 504-514. doi: 10.1016/s0006-3223(03) 00168-9

Piguet, O., Connally, E., Krendl, A. C., Huot, J. R., and Corkin, S. (2008). False memory in aging: effects of emotional valence on word recognition accuracy. Psychol. Aging 23, 307-314. doi: 10.1037/0882-7974.23.2.307

Posner, M. I., and Petersen, S. E. (1990). The attention system of the human brain. Annu. Rev. Neurosci. 13, 25-42. doi: 10.1146/annurev.ne.13.030190. 000325

Prakash, R. S., De Leon, A., Klatt, M., Malarkey, W., and Patterson, B. (2013). Mindfulness disposition and default-mode network connectivity in older adults. Soc. Cogn. Affect. Neurosci. 8, 112-117. doi: 10.1093/scan/ nss 115

Prakash, R. S., Erickson, K. I., Colcombe, S. J., Kim, J. S., Voss, M. W., and Kramer, A. F. (2009). Age-related differences in the involvement of the prefrontal cortex in attentional control. Brain Cogn. 71, 328-335. doi: 10.1016/j.bandc.2009. 07.005

Prakash, R. S., Heo, S., Voss, M. W., Patterson, B., and Kramer, A. F. (2012). Agerelated differences in cortical recruitment and suppression: implications for cognitive performance. Behav. Brain Res. 230, 192-200. doi: 10.1016/j.bbr.2012. 01.058

Raichle, M. E., MacLeod, A. M., Snyder, A. Z., Powers, W. J., Gusnard, D. A., and Shulman, G. L. (2001). A default mode of brain function. Proc. Natl. Acad. Sci. U S A 98, 676-682. doi: 10.1073/pnas.98.2.676

Ramel, W., Goldin, P. R., Carmona, P. E., and McQuaid, J. R. (2004). The effects of mindfulness meditation on cognitive processes and affect in patients with past depression. Cognit. Ther. Res. 28, 433-455. doi: 10.1023/b:cotr.0000045557. 15923.96

Raz, N. (2000). "Aging of the brain and its impact on cognitive performance: integration of structural and functional findings," in The Handbook of Aging and Cognition-II, eds F. I. M. Craik and T. A. Salthouse (Mahwah, NJ: Erlbaum), $1-90$.

Raz, N., Lindenberger, U., Rodrigue, K. M., Kennedy, K. M., Head, D., Williamson, A., et al. (2005). Regional brain changes in aging healthy adults: general trends, individual differences and modifiers. Cereb. Cortex 15, 1676-1689. doi: 10.1093/ cercor/bhi044

Rebok, G. W., Carlson, M. C., and Langbaurn, J. B. S. (2007). Training and maintaining memory abilities in healthy older adults: traditional and novel approaches. J. Gerontol. B Psychol. Sci. Soc. Sci. 62, 53-61. doi: 10.1093/geronb/ 62.special_issue_1.53 
Reed, A. E., and Carstensen, L. L. (2012). The theory behind the agerelated positivity effect. Front. Psychol. 3:339. doi: 10.3389/fpsyg.2012. 00339

Reuter-Lorenz, P. A., and Mikels, J. (2006). "The aging brain: implications of enduring plasticity for behavioral and cultural change," in Lifespan Development and the Brain: The Perspective of Biocultural Co-Constructivism, eds P. Baltes, P. A. Reuter-Lorenz and F. Roesler (New York, NY: Cambridge University Press), 255-276.

Reuter-Lorenz, P. A., and Park, D. C. (2010). Human neuroscience and the aging mind: a new look at old problems. J. Gerontol. B Psychol. Sci. Soc. Sci. 65B, 405415. doi: 10.1093/geronb/gbq035

Reuter-Lorenz, P. A., Jonides, J., Smith, E. E., Hartley, A., Miller, A., Marshuetz, C., et al. (2000). Age differences in the frontal lateralization of verbal and spatial working memory revealed by PET. J. Cogn. Neurosci. 12, 174-187. doi: 10. 1162/089892900561814

Ritchey, M., Bessette-Symons, B., Hayes, S. M., and Cabeza, R. (2011). Emotion processing in the aging brain is modulated by semantic elaboration. Neuropsychologia 49, 640-650. doi: 10.1016/j.neuropsychologia.2010. 09.009

Rosenkranz, J. A., Moore, H., and Grace, A. A. (2003). The prefrontal cortex regulates lateral amygdala neuronal plasticity and responses to previously conditioned stimuli. J. Neurosci. 23, 11054-11064.

Rozin, P., and Royzman, E. B. (2001). Negativity bias, negativity dominance and contagion. Pers. Soc. Psychol. Rev. 5, 296-320. doi: 10.1207/s15327957 pspr0504_2

Rush, B. K., Barch, D. M., and Braver, T. S. (2006). Accounting for cognitive aging: context processing, inhibition or processing speed. Neuropsychol. Dev. Cogn. B Aging Neuropsychol. Cogn. 13, 588-610. doi: 10.1080/138255806006 80703

Sahdra, B. K., MacLean, K. A., Ferrer, E., Shaver, P. R., Rosenberg, E. L., Jacobs, T. L., et al. (2011). Enhanced response inhibition during intensive meditation training predicts improvements in self-reported adaptive socioemotional functioning. Emotion 11, 299-312. doi: 10.1037/a0022764

Salovey, P., and Mayer, J. D. (1990). Emotional intelligence. Imagin. Cogn. Pers. 9, 185-211. doi: 10.2190/DUGG-P24E-52WK-6CDG

Salthouse, T. A. (2010). Selective review of aging. J. Int. Neuropsychol. Soc. 16, 754 760. doi: 10.1017/S1355617710000706

Samanez-Larkin, G. R., and Carstensen, L. L. (2011). "Socioemotional functioning and the aging brain," in The Oxford Handbook of Social Neuroscience, ed J. D. J. T. Cacioppo (New York, NY: Oxford University Press), 507-521.

Scheibe, S., and Blanchard-Fields, F. (2009). Effects of regulating emotions on cognitive performance: what is costly for young adults is not so costly for older adults. Psychol. Aging 24, 217-233. doi: 10.1037/a0013807

Segal, Z. V., Williams, J. M. G., and Teasdale, J. D. (2002). Mindfulness based Cognitive Therapy for Depression. New York, NY: Guilford Press.

Shadish, W. R., Cook, T. D., and Campbell, D. T. (2002). Experimental and QuasiExperimental Designs for Generalized-Causal Inference. Boston, MA: Houghton Mifflin Company.

Shamaskin, A. M., Mikels, J. A., and Reed, A. E. (2010). Getting the message across: age differences in the positive and negative framing of health care messages. Psychol. Aging 25, 746-751. doi: 10.1037/a0018431

Shiota, M. N., and Levenson, R. W. (2009). Effects of aging on experimentally instructed detached reappraisal, positive reappraisal and emotional behavior suppression. Psychol. Aging 24, 890-900. doi: 10.1037/a0017896

Shulman, G. L., Astafiev, S. V., McAvoy, M. P., d'Avossa, G., and Corbetta, M. (2007). Right TPJ deactivation during visual search: functional significance and support for a filter hypothesis. Cereb. Cortex 17, 2625-2633. doi: 10. 1093/cercor/bhl170

Shulman, G. L., Corbetta, M., Fiez, J. A., Buckner, R. L., Miezin, F. M., Raichle, M. E., et al. (1997). Searching for activations that generalize over tasks. Hum. Brain Mapp. 5, 317-322. doi: 10.1002/(SICI)1097-0193(1997)5:4<317::AIDHBM19>3.0.CO;2-A

Smallwood, J., Tipper, C., Brown, K., Baird, B., Engen, H., Michaels, J. R., et al. (2013). Escaping the here and now: evidence for a role of the default mode network in perceptually decoupled thought. Neuroimage 69, 120-125. doi: 10 . 1016/j.neuroimage.2012.12.012

Stawarczyk, D., Majerus, S., Maquet, P., and D'argembeau, A. (2011). Neural correlates of ongoing conscious experience: both task-unrelatedness and stimulus-independence are related to default network activity. PLoS One 6:e16997. doi: 10.1371/journal.pone.0016997

Story, T. N., Berg, C. A., Smith, T. W., Beverridge, R., Henry, N. M. J., and Pearce, G. (2007). Age, marital satisfaction and optimism as predictors of positive sentiment override in middle aged and older married couples. Psychol. Aging 24, 719-727. doi: 10.1037/0882-7974.22.4.719

Suri, G., and Gross, J. J. (2012). Emotion regulation and successful aging. Trends Cogn. Sci. 16, 409-410. doi: 10.1016/j.tics.2012.06.007

Tamber-Rosenau, B. J., Esterman, M., Chiu, Y.-C., and Yantis, S. (2011). Cortical mechanisms of cognitive control for shifting attention in vision and working memory. J. Cogn. Neurosci. 23, 2905-2919. doi: 10.1162/jocn.2011. 21608

Tang, Y. Y., Ma, Y., Wang, J., Fan, Y., Feng, S., Lu, Q., et al. (2007). Short-term meditation training improves attention and self-regulation. Proc. Natl. Acad. Sci. U S A 104, 17152-17156. doi: 10.1073/pnas.0707678104

Tang, Y. Y., and Posner, M. I. (2009). Attention training and attention state training. Trends Cogn. Sci. 13, 222-227. doi: 10.1016/j.tics.2009. 01.009

Taylor, V. A., Grant, J., Daneault, V., Scavone, G., Breton, E., Roffe-Vidal, S., et al. (2011). Impact of mindfulness on the neural responses to emotional pictures in experienced and beginner meditators. Neuroimage 57, 1524-1533. doi: 10 1016/j.neuroimage.2011.06.001

Teasdale, J. T., Segal, Z. V., Williams, J. M. G., Ridgeway, V. A., Soulsby, J. M., and Lau, M. A. (2000). Prevention of relapse/recuurence in major depression by mindfulness-based cognitive therapy. J. Consult. Clin. Psychol. 68, 615-623. doi: 10.1037/0022-006X.68.4.615

Urry, H. L., and Gross, J. J. (2010). Emotion regulation in older age. Curr. Dir. Psychol. Sci. 19, 352-357. doi: 10.1177/0963721410388395

Urry, H. L., van Reekum, C. M., Johnstone, T., Kalin, N. H., Thurow, M. E., Schaefer, H. S., et al. (2006). Amygdala and ventromedial prefrontal cortex are inversely coupled during regulation of negative affect and predict the diurnal patter of cortisol secretion among older adults. J. Neurosci. 26, 4415-4425. doi: 10.1523/jneurosci.3215-05.2006

Vago, D. R., and Silbersweig, D. A. (2012). Self-awareness, self-regulation and selftranscendence (S-ART): a framework for understanding the neurobiological mechanisms of mindfulness. Front. Hum. Neurosci. 6:296. doi: 10.3389/fnhum. 2012.00296

van den Hurk, P. A. M., Giommi, F., Gielen, S. C., Speckens, A. E. M., and Barendregt, H. P. (2010a). Greater efficiency in attentional processing related to mindfulness meditation. Q. J. Exp. Psychol. (Hove) 63, 1168-1180. doi: 10. 1080/17470210903249365

van den Hurk, P. A. M., Janssen, B. H., Giommi, F., Berendregt, H. P., and Gielen, S. C. (2010b). Mindfulness meditation associated with alterations in bottom-up processing: psychophysiological evidence for reduced reactivity. Int. J. Psychophysiol. 78, 151-157. doi: 10.1016/j.ijpsycho.2010. 07.002

Velanova, K., Lustig, C., Jacoby, L. L., and Buckner, R. L. (2007). Evidence for frontally mediated controlled processing differences in older adults. Cereb. Cortex 17, 1033-1046. doi: 10.1093/cercor/bhl013

Williams, J. M. G. (2010). Mindfulness and psychological process. Emotion 10, 1-7. doi: $10.1037 / \mathrm{a} 0018360$

Williams, L. M., Brown, K. J., Palmer, D., Liddell, B. J., Kemp, A. H., Olivieri, G., et al. (2006). The mellow years? Neural basis of improving emotional stability over age. J. Neurosci. 26, 6422-6430. doi: 10.1523/JNEUROSCI.0022-06. 2006

Willis, S. L., Tennstedt, S. L., Marsiske, M., Ball, K., Elias, J., Koepke, K. M., et al. (2006). Long-term effects of cognitive training on everyday functional outcomes in older adults. JAMA 296, 2805-2814. doi: 10.1001/jama.296.23. 2805

Winecoff, A., Labar, K. S., Madden, D. J., Cabeza, R., and Huettel, S. A. (2011). Cognitive and neural contributors to emotion regulation in aging. Soc. Cogn. Affect. Neurosci. 6, 165-176. doi: 10.1093/scan/nsq030

Xiong, G. L., and Doraiswamy, P. M. (2009). Does meditation enhance cognition and brain plasticity? Ann. N Y Acad. Sci. 1172, 63-69. doi: 10.1196/annals. 1393.002

Yeung, D. Y., Fung, H. H., and Lang, F. R. (2008). Self-construal moderates age differences in social network characteristics. Psychol. Aging 23, 222-226. doi: 10. 1037/0882-7974.23.1.222 
Zeidan, F., Johnson, S. K., Diamond, B. J., David, Z., and Goolkasian, P. (2010). Mindfulness meditation improves cognition: evidence of brief mental training. Conscious. Cogn. 19, 597-605. doi: 10.1016/j.concog.2010. 03.014

Ziegler, G., Dahnke, R., Jäncke, L., Yotter, R. A., May, A., and Gaser, C. (2012). Brain structural trajectories over the adult lifespan. Hum. Brain Mapp. 33, 23772389. doi: 10.1002/hbm.21374

Conflict of Interest Statement: The authors declare that the research was conducted in the absence of any commercial or financial relationships that could be construed as a potential conflict of interest.
Received: 21 November 2013; accepted: 27 May 2014; published online: 24 June 2014. Citation: Prakash RS, De Leon AA, Patterson B, Schirda BL and Janssen AL (2014) Mindfulness and the aging brain: a proposed paradigm shift. Front. Aging Neurosci. 6:120. doi: 10.3389/fnagi.2014.00120

This article was submitted to the journal Frontiers in Aging Neuroscience.

Copyright (c) 2014 Prakash, De Leon, Patterson, Schirda and Janssen. This is an openaccess article distributed under the terms of the Creative Commons Attribution License (CC BY). The use, distribution or reproduction in other forums is permitted, provided the original author(s) or licensor are credited and that the original publication in this journal is cited, in accordance with accepted academic practice. No use, distribution or reproduction is permitted which does not comply with these terms. 